JAMES FORREST LECTURE, 1962

\title{
SPACE FLIGHT AND ROCKETS
}

\author{
by \\ Geoffrey Keith Charles Pardoe, B.Sc.(Eng.), D.L.C., A.F.R.Ae.S. \\ Chief Engineer (Weapons and Space Research Group) \\ The de Havilland Aircraft Co. Ltd.
}

\section{INTRODUCTION}

I AM very conscious of the honour of being asked to deliver this lecture to you today, particularly when I recall those eminent people, who have given it in preceding years. I console myself that perhaps the disadvantage that I may have in shorter experience, may be offset by the fact that space technology itself has not been in existence for many years. Already, however, in the 4 years since October 4, 1957, when the first man-made satellite was injected into orbit, there have been tremendous advances made-not only in the creation of techniques and apparatus to conduct such work, but in the new knowledge that has come to us, by the use of this new means of research the world now possesses. I think it is significant too, that already we have a very good idea of the type of space activity with which the world will concern itself in the next 10 years or so. Indeed this present decade is planned in considerable detail, publicly by the Americans-and undoubtedly privately by the Russians. It would be most interesting to look back in the archives, and study the contents of a lecture, similar to this, given in the year 1907, 4 years or so after the first heavier-than-air craft had flown. I would venture to suggest that they then had far less idea of the potentiality of the aeroplane and about its enormous impact in the ways of the world, than we have today about space-relatively ignorant though we are, about our new-found ability. This in itself is encouraging.

The fantasy of space flight has existed for so many centuries-even thousands of years-that it is not really surprising that it is taking a few years for people to adjust themselves to the full meaning of the reality. Not only has space flight ceased to be fiction, but it is already the source of vast commercial business, and has fundamentally serious implications in international economics, politics, and military strategy. This transition, or phase of realization, will undoubtedly stay with us for some time, although in the relatively near future, the people of the world will begin to feel the direct influence, and benefits, of the use of space.

The key to man's ability to enter space, has of course, been the development of sufficient propulsive power. In theory one can leave the earth in a vertical direction by continuously applying force upwards to overcome the local effect of gravity. In practice, however, this is very wasteful in terms of energy, and our rockets today turn away from the vertical path soon after take-off, subsequently accelerating the vehicle to sufficient speed above the atmosphere to produce a state of equilibrium between gravity and centrifugal force in the orbital 
condition, alternatively projecting the payload at even greater "escape" velocities so that even after decelerating to infinity a positive speed is always maintained away from the earth and the space probe enters the broader gravitational fields of influence of the sun and the solar system. We are confined to this system and the space around it for many decades to come for this reason:

Light at 186,000 miles per second takes just over a second to travel from earth to the moon, nearly nine minutes to the sun, four and a quarter years to our nearest star Proxima Centauri B, and over one million years to our nearest galaxy, Andromeda. The position of the solar system in relation to our own Galaxy can be seen by the arrow in Fig. 9* which is an artist's impression.

Even the most optimistic among us would agree that travel of man-made objects at the speed of light is some time away, so that using a modest velocity of $250,000 \mathrm{~m}$.p.h. (which is ten times the rocket speed yet achieved) it would take over 11,000 years to reach the vicinity of the nearest star. Our space fiction writers still have plenty of scope with interstellar and intergalactic travel. It can be seen that we are yet contemplating only the inner fringes of outer space.

\section{The basic technology}

Development of the ballistic missile provided the first foothold in space. The large-thrust rocket engines, evolved from the principles demonstrated so forciably by the V2 twenty years ago-provided the power to lift the ballistic missiles of the 1950s into their sub-orbital flights. These rocket engines not only had to be large enough to lift the dead weight of structure, tanks, and engines from the ground but also the propellants feeding them had to be efficient and light enough to keep the engines burning long enough to accelerate the whole to the required speed. Clearly the minimum vehicle dry weight, for the maximum of enclosed tankage within the lift-off thrust capability of the engines, is the key requirement. With the state of technology then and now (and for some considerable time to come) it is necessary to "stage" the rockets to achieve the velocities required for orbital flight-about $25,000 \mathrm{ft} / \mathrm{sec}$. or more for orbital flight, about $37,000 \mathrm{ft} / \mathrm{sec}$. or more to achieve escape velocity away from the earth's gravitational field. For the early American rockets the payload, (the actual satellite), was as little as $0.03 \%$ of the lift-off weight of the rocket on the pad for the Explorer series, and $0.1 \%$ for the Vanguard. The Vanguard rocket itself was interesting, althought not particularly successful in operation, being the first rocket designed specifically to meet the requirements of space flight for the International Geophysical Year of 1957. As a measure of the improvement in technology, the current American satellites launched in orbit such as Samos and Discoverer, are as much as $0.5 \%$ of the take-off weight of the complete vehicle on the launching pad. With the evolution of space flight it will be necessary to increase this ratio of payload to the all-up weight as much as possible, otherwise clearly for large orbital requirements, monster rockets even by today's standards would be required at lift-off. Payload ratios of 20 or $30 \%$ or more may well be achieved later on by the use of nuclear propulsion and other devices.

Propulsion AND CONTROL

At present, liquid propellants provide higher specific impulses (thrust per

- Figs 9-25 are photographs and are placed between pp. 368-369. 
pound of propellant used per second) than the solid propellants. The diagram (Fig. 1) shows a selection of various combinations of fuel and oxidant, the most popular to date being liquid oxygen and kerosene which has powered the American Thor, Atlas, and Saturn rockets, and the British Blue Streak. Towards the upper end of the scale, liquid oxygen and liquid hydrogen provide a great attraction with sea-level specific impulses of some 360 seconds. This combination of so-called "exotic propellants" will shortly be used in the American Centaur high-energy stage for the Atlas vehicle to provide a much improved payload capability. Hydrogen and fluorine provide an even greater specific impulse, but at present the added difficulties of handling the fluorine militate against its extensive use. The improvement to be expected in the next generation of rockets is therefore to sea-level specific impulses in the order of 360 seconds. Fig. 1 has been plotted against exhaust velocity; indeed the

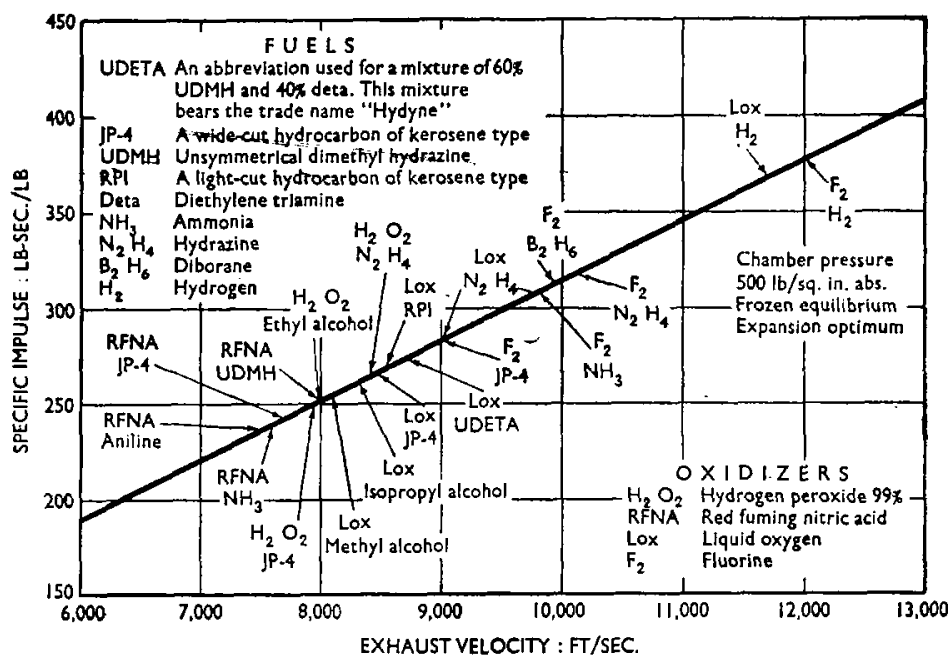

Fig. 1.-Performance of SOME Liquid FUEL/OXIDANT COMBINATIONS

velocity at burn-out $\left(V_{\mathrm{b}}\right)$ at the end of the propulsion stage in free space is related to the effective exhaust velocity $c$ of the rocket, and to the mass ratio $m$ by the equation $V_{\mathrm{b}}=c \log _{\mathrm{e}} m+V_{0}-V_{\mathrm{g}}-V_{\mathrm{d}}$ where $V_{0}$ is the vehicle velocity at the ignition of the stage considered. $V_{\mathrm{g}}$ and $V_{\mathrm{d}}$ are equivalent velocity decrements caused by gravitational and drag losses respectively. Clearly therefore, the higher exhaust velocity and mass ratio, the better. Typical values of exhaust velocity at present are around 8,000 ft/sec. and later some $11,000 \mathrm{ft} / \mathrm{sec}$. Fig. 2 shows mass ratio for various specific impulses, plotted against the velocity increment in $\mathrm{ft} / \mathrm{sec}$. of the stage, and it can be seen that, taking the case of a single stage rocket, for 260 secs (an exhaust velocity of $8,372 \mathrm{ft} / \mathrm{sec}$ ) the velocity decrement is $15,000 \mathrm{ft} / \mathrm{sec}$ for a mass ratio of $6: 1$. If this were representative of the first stage of a rocket, then a further $10,000 \mathrm{ft} / \mathrm{sec}$ must be achieved by the use of a further stage, starting after this boost has finished burning. As a matter of interest in 1958 an American Atlas rocket stripped down to the bare essentials, lengthened, and carrying only a tape recorder and power supply, managed to 
place itself into an orbit of height 180 miles above the earth; this actually had one and a half stages (a half stage-the two booster engines without tanks-was dropped off).

Generally, the multi-stage configuration is used, and the velocity increments are computed in a more refined manner taking practical engineering factors into account. Liquid-fuel rockets have an advantage over solid fuels in flexibility of use and higher efficiency in the space application, but recently a four-stage solid-fuel rocket, "Scout" has launched satellites into orbit; this was specifically designed for space and has no military designation at all.

Directional control of a main stage rocket in space is generally exercised by swivelling the thrust chamber on a pivot by means of hydraulic jacks; this function is initiated by a complex auto-pilot control system which in turn

SEA.LEVEL SPECIFIC IMPULSE. LB/LB OF PROPELLANT USED/SEC

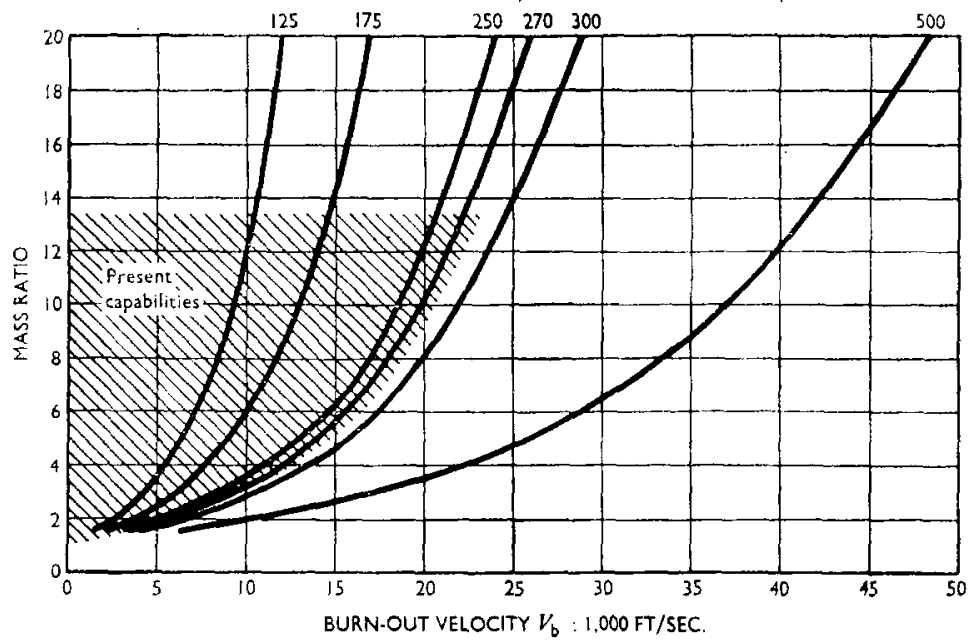

FIG. 2.- VARIATION OF BURN-OUT VELOCITY WITH MASS RATIO FOR VARIOUS VALUES OF SPECIFIC IMPULSE, IN SINGLE-STAGE ROCKETS

receives its steering signals either from the inertial navigation equipment on board the vehicle, or from remote radio command generated from a ground station which is tracking the vehicle by optical or radar methods. The combustion chambers of the engines are usually fed by a turbo-pump system, propellants being fed from tanks, themselves pressurized to prevent cavitation; in certain instances such as Atlas and Blue Streak, tank pressurization also provides structural stiffness, as the tank-wall for Blue Streak is only 0.019 in. thick and after leaving its handling frame requires internal pressurization the whole time it is on the ground or in flight. Many variations of this liquid-fuel rocket propulsion system can be found in detail but the broad principles apply.

Sizes have increased gradually with time, and whilst the early ballistic missile V2 had a single engine with a thrust of $60,000 \mathrm{lb}$, current thrusts of a single engine of $150,000 \mathrm{lb}$ are common; the first "Saturn" vehicle recently flown in 
America had eight such engines producing a combined thrust of over $1 \frac{1}{2}$ million $\mathbf{l b}$. North American Aviation Co. in America have for many months now been ground-testing the $F 1$ engine with a thrust of $1 \frac{1}{2} \mathrm{~m} \mathrm{lb}$.; this requires, as you may imagine, an enormous combustion chamber as shown in Fig. 10 with a diameter of some $10 \mathrm{ft}$ at the base.

At present it is only the use of chemical rockets of the type described, that provides the large thrusts to lift the overall vehicle from the ground. However, once clear of the atmosphere, and of the decreasing influence of gravity, alternative lower-thrust propulsive systems can be contemplated. One of the most obvious prime sources of power is nuclear energy. In America for example, they have for some years been testing the Kiwi series of nuclear rockets aimed at producing an in-flight engine with a thrust of some $55,000 \mathrm{lb}$. The flight versions of this will be called the Rover rocket, and will be tested in the coming RIFT project (Reactor In Flight Tests). The basic principle of this nuclear rocket is shown in Fig. 3; it can be seen that the nuclear reactor contains tubes through

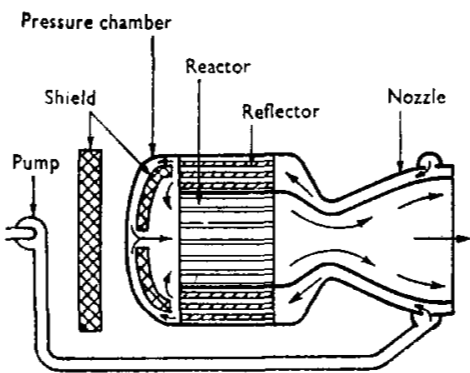

DISPERSED FUEL-IN.GRAPHITE REACTOR

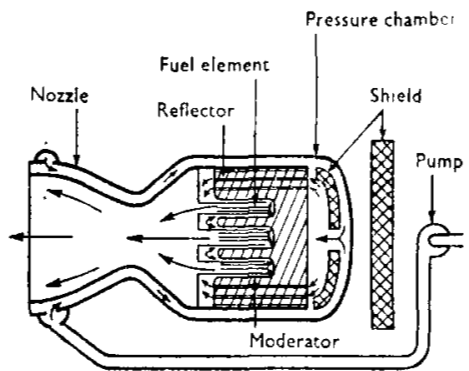

TUNGSTEN FUEL-ELEMENT-IN-BeO REACTOR

FIG. 3.-DiAgRAMMATIC LAYOUT OF TWO FORMS OF NUCLEAR ROCKET MOTOR

which the working fluid (hydrogen) is passed, heated, and ejected at high velocity. The element of lowest atomic weight, hydrogen, is used since the lower the molecular weight, the higher is the exhaust velocity, with the advantages outlined previously. Naturally, such an arrangement produces a highly radioactive efflux, and if used as a propulsive system for the first stage of a vehicle would contaminate the launching site for a considerable time. The nuclear rocket quite apart from the relatively low thrust at this time of development, clearly has best application for upper stage work until a "clean" efflux system can be developed. We can expect specific impulses of a nuclear system to be in the order of $1,000 \mathrm{sec}$.- a considerable improvement on basic chemical techniques.

Later developments may possibly utilize gaseous reactors in which the fissile fuel material and working fluid are injected and mixed together in the reaction chamber. Yet a further nuclear propulsion system conceived is the controlled bomb, in which motion is imparted to a vehicle by firing, in series, a number of small controlled-output fission bombs; the bomb capsules to be fired are injected into a spherical thrust chamber and exploded at the appropriate time and position by fuses. It need hardly be added that such a development will not become economically attractive, (if attractive is the right word at all) until extremely high 
weights and payloads become a necessity. I would think the feasibility of contained nuclear "explosions" would have to be carefully considered too.

Fig. 4 shows the relationship between energy sources, energy converters, and thrust devices.

A more immediate, and most important, propulsion technique is based on electrical energy: there are various types of electric drive; one example is electrothermal drive (sometimes known as arc jet) which is similar to chemical and nuclear propulsion methods insofar as the acceleration of the propellant is caused primarily by thermo-dynamic expansion-the chemical combustion chamber being replaced by an electric-arc generator. It has inherent ability to operate efficiently at specific impulses from 500 to, say, 2,000 seconds, hence it is capable

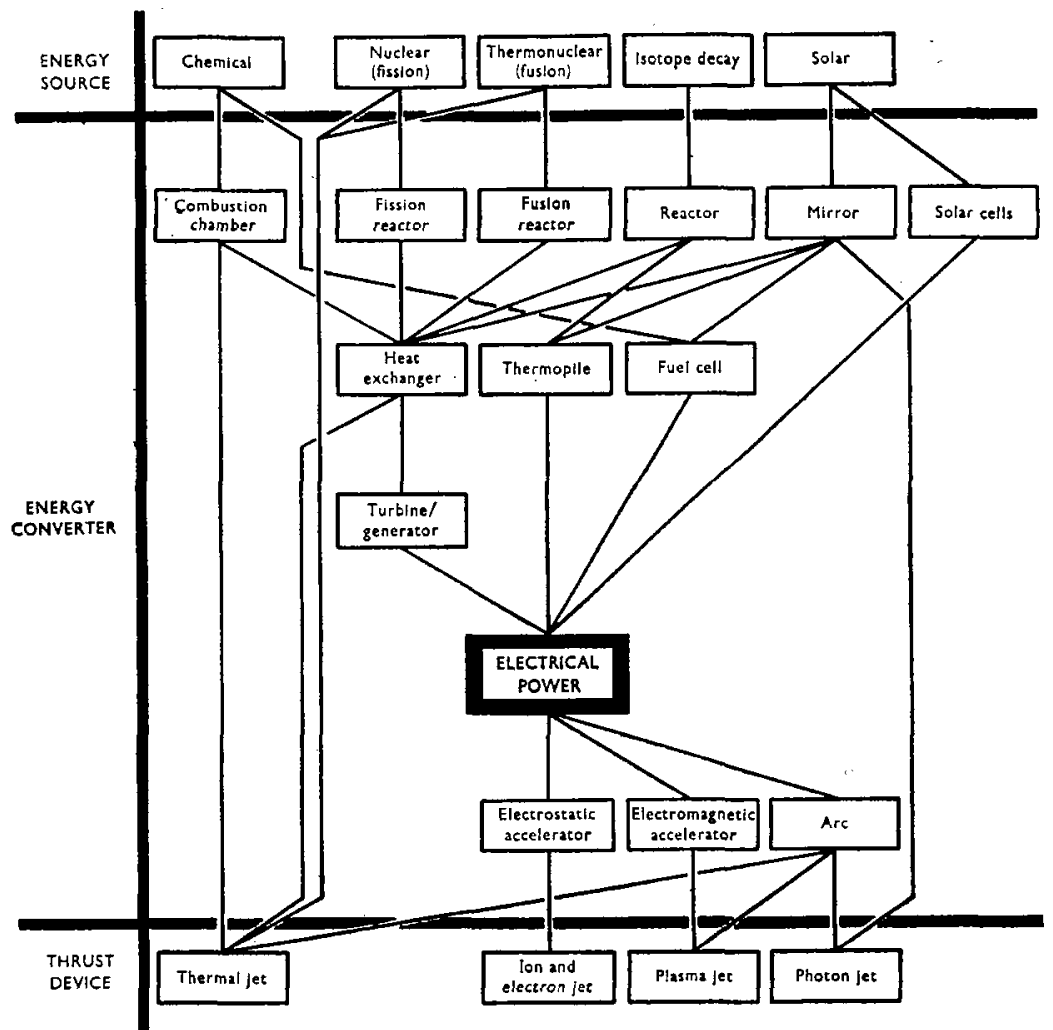

Fig. 4.-Propulsion SYstems AND electrical POWER Relationship

of producing relatively high thrusts. Another electric drive is the magnetohydrodynamic plasma drive. The plasma propulsion systems involve the generation and acceleration of highly ionized gases. They differ from the foregoing arc jet system, fundamentally, because there is no thermo-dynamic expansion cycle; the exhaust jet still being substantially a plasma. The systems have inherent ability to operate efficiently at specific impulses above 1,500 seconds. 
Yet another method is the electrostatic or ion motor which, like magnetohydrodynamic propulsion systems, does not involve a thermodynamic expansion cycle, and the exhaust similarly is a highly ionized plasma (hence the energy of ionization is lost). The monomolecular working fluid is electrostatically accelerated and expelled in a high-velocity beam, or jet, to provide thrust at high efficiencies at specific impulses above about 5,000 seconds.

The fundamental distinction of electrical propulsion systems is their inherent thrust controllability and the high exhaust velocity combined with a low rate of mass flow. All types require, however, large amounts of electrical power measured in kilowatts, one example being an ion system with a resultant thrust of $0.05 \mathrm{lb}$. Clearly for such levels of electric power a nuclear energy source is required. Furthermore, with such a low thrust the system is best suited to a long term mission-either controlling the position or attitude of a satellite in orbit, or producing velocity changes to space probes during an interplanetary mission (the propulsion duration therefore measured in weeks or years). In terms of required propellant weight for a given mission, electric drive is greatly superior to chemical rockets and there will be tremendous applications and evolution of these techniques. Already in America several electric drive systems are working; one of which, shown in Fig. 11, is the Hughes system. Caesium vapour is ionized by a hot, tungsten element and the ions are accelerated electrically to provide the exhaust stream. Electrons are injected to avoid attraction between the vehicle and a charged exhaust. The thrust developed, for a power consumption between one and two $\mathrm{KW}$, is less than $1 / 10 \mathrm{lb}$. It is hoped that the Hughes ion rocket will be flight-tested on an American Scout rocket later this year.

Yet further propulsive systems contemplated use of various types of radiation. This generally is considered to be beyond our present state of knowledge but for interest one may mention a few examples: one method would involve the collection and concentration of the radiation from the sun, using it to heat a working fluid such as hydrogen, which would then be expanded and exhausted through a nozzle. Large collecting areas would be needed and its use would be restricted to regions relatively close to the sun-say within 200 million miles. Direct solar radiation is another method, in which the pressure of solar radiation on a large surface-a solar sail-causes thrust; again the area required for a small thrust is enormously large-for example, at 100,000 miles from the sun radiation pressure is only of the order of $0.01 \mathrm{lb} /$ acre. Nevertheless, sometimes this is not without application in interplanetary work. A less practical method is the photon drive - a photon being a quantum of electromagnetic radiation of visible or invisible wavelength, moving at the speed of propagation of light. It may be considered in terms of wave motion, or as a particle of zero rest-mass. Photon radiation is not influenced by electric or magnetic fields and consequently can only be formed into a propulsive beam by reflexion. Thrust would thus be obtained from the momentum of a beam of photons emitted by heated objects (for example, an incandescent filament) or by direct radiation from a nuclear power source. The specific impulse of the beam has the impressive figure of 30 million seconds (the finite upper limit to any form of propulsion) but although the photon drive has such an inherently high specific impulse, present forms of energy conversion make the system completely impracticable. For example, thrust is approximately only $0.0000007 \mathrm{lb} /$ kilowatt of power dissipation in a modern searchlight i.e. a photon beam. 
I have considered the propulsive systems at length because they are indeed the basis of all space work, and yet even this survey does not reach far enough into requirements of thrust and efficiency, and it may well be that evolutions of electromagnetic energy-harnessing principles, avoiding momentum change with the inherent loss of mass of the vehicle, will become practicable and applicable in later decades. In the mean time great effort is being expended on the improvements on chemical, nuclear, and electric methods; particular attention must be given controlling the level of thrust, because this is a necessity to enable space probes, and later manned craft, to be decelerated from orbits established around the moon or planet and let down to the surface. Not only therefore will the improvement of all forms of propulsion technology be demanded, but all aspects of control system engineering will be stimulated enormously by the stringent requirements for such missions.

Let it not be thought however, that objectives in this new field of technology are geared to more exotic deep space requirements-the effort of many of us is devoted firmly to basic engineering developments of techniques already known, aimed at producing reliable equipment for use in the near-earth environment on scientific research, civil, and military space missions.

\section{POWER AND ELECTRONICS}

In the time available I shall not attempt to go into detail on many other fields of technology associated with such work; there are however one or two which deserve particular merit. One is that of electric power generation on which we have touched already. With few exceptions every space payload requires electrical power. In nearly all cases so far, this has been derived from storage batteries generally augmented by solar cells operating whilst in view of the sun. More recently a radio-isotope electrical supply system has been successfully tested in space-the SNAP III Reactor, weighing $4.5 \mathrm{lb}$ with a power output of 3 watts. Not only are high reliable power levels demanded, but also for a considerable length of time-a typical communication satellite requiring continuous power for a period of 5 to 20 years.

Enormous strides are being made in this field of technology, and much new knowledge is being gained with general application to more orthodox branches of engineering.

Associated clearly with the electrical power requirement is the need for new forms of electronic equipment. Space technology has stimulated the evolution of micro-miniaturized components, circuits, and systems. At present, for every added $\mathrm{lb}$ weight of the satellite, about $100 \mathrm{lb}$ weight of the first-stage vehicle is required: every ounce saved in the "business" end of the vehicle is vital and it is not surprising, therefore, that equipment is already being developed or produced with a density of between 300-1,500 units per cubic inch. Table 1 shows the general order of micro-miniaturization which can be expected with past, present, and future techniques. It can be said about micro-miniaturization (as indeed about many other of the indirect benefits of conducting space activity) that certain other forms of activity not in space would stimulate similar development. This is undoubtedly true but the challenge provided by the extreme requirements of the space environment provides the greatest stimulus.

\section{GROUND SUPPORT EQUIPMENT}

A vital feature of ballistic programmes is the extensive requirement for ground 
TABLE 1.--AVERAGE COMPONENT DENSITIES FOR DIFFERENT CONSTRUCTIONAL TECHNIQUES

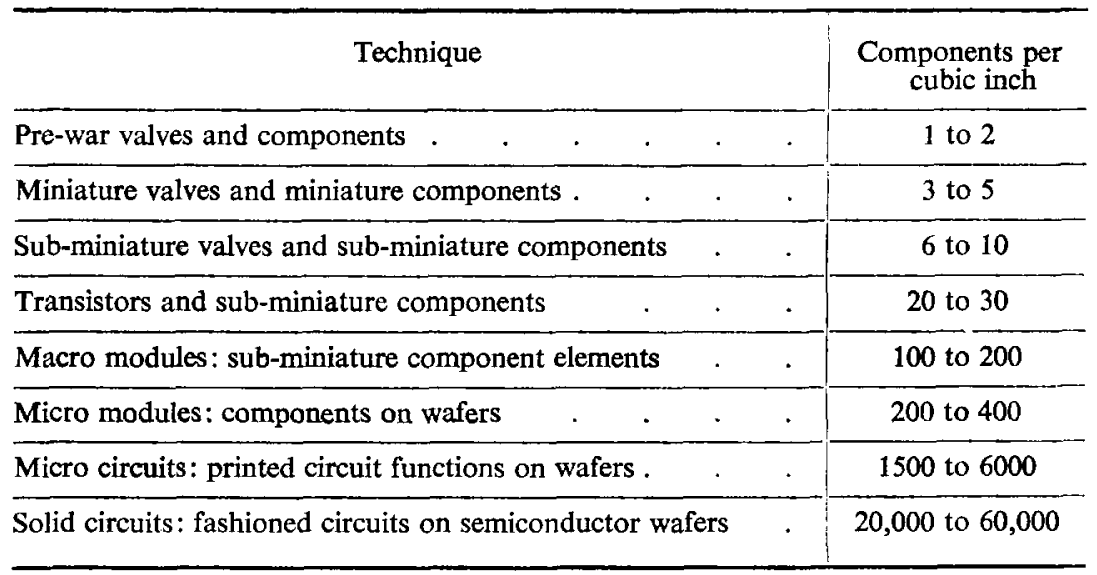

support equipment at all stages in development and production. Not only must special electronic check-out and recording equipment be designed such as that for Blue Streak shown in Fig. 12, but special handling and transport arrangements must be made to move the enormous, and yet sometimes fragile structures from place to place. At the test stands where the propulsion systems are run, as seen in Fig. 13 with the twin engine firing, the wide spectrum of engineering skills associated with this work becomes readily apparent. At one extreme, the enormous civil engineering works can be seen (Fig. 14) at Spadeadam in Cumberland, where Blue Streak is tested. One item of interest on this Blue Streak test stand (Fig. 15) is the water-cooled efflux deflector, some $30 \mathrm{ft}$ diameter. Alternative deflectors are of specially designed concrete of suitably low erosion rates in the presence of rocket efflux deflexion as in the Blue Streak launching pad at Woomera (Fig. 16). Towers, some $150 \mathrm{ft}$ high (capable of being rolled back several hundreds of feet from the launching pad) are used for servicing the vehicles, again seen (Fig. 17) at Spadeadam. Not the least of the problems of civil and mechanical design is the fact that the launching pads and test sites must be in remote places (the middle of deserts, on islands, or in desolate wastes of countryside) each requiring their special civil problems of establishing communities, and production plants for liquid propellants etc., as well as the test stands.

So many different forms of science and technology are embraced by this new field of space flight that one can always be sure of relating some part of the work to any institution or society that may be interested to discuss this new field; certainly civil engineering forms a very vital part in its accomplishment. The photograph (Fig. 18) of the servicing tower of the Saturn launching complex in the U.S.A. at Cape Canaveral gives some idea of the trend in large civil and mechanical engineering structures required for such work. This tower stands some $300 \mathrm{ft}$ high, weighing 2,540 tons and is moved back $600 \mathrm{ft}$ along rails at launch.

The geographical location of the launching site is of great significance; ideally launching sites, for most space work, should be located on the equator where the 
earth has a tangential surface component in an easterly direction of some $1,500 \mathrm{ft}$ / sec.-not an insignificant contribution to the velocity required of the vehicle after it is launched and turned over into the near-horizontal plane. However, at present no such site exists on the equator-Cape Canaveral is nearly $30^{\circ} \mathrm{N}$ in latitude, Woomera is some $31^{\circ} \mathrm{S}$ and the Russian sites near the Aral Sea are some $47^{\circ} \mathrm{N}$. At least the Russian and American ranges have an easterly component whereas at Woomera the present space firings are contemplated only in a near-northerly direction. Since the easterly equatorial orbit is of considerable interest, it is therefore very important to establish a corridor from Woomera in an easterly or north-easterly direction because the rocket energy wasted in changing orbit planes is enormous. It is inevitable that before the next decade has gone by, plans will be made for a launching site to be established on or near the equator, but, in the mean time, we must make the best use of the facilities we have.

Again I need hardly stress the civil engineering aspects of constructing an equatorial site and range, the cost of which will undoubtedly be in the order of

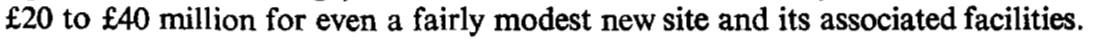

\section{OTHER FACTORS}

In discussing basic technology, one must not gloss over the new problems of guidance and navigation, which I now record only in passing. Astro-navigation is a new science in its own right. Not dealt with also, are problems of radio propagation, ground tracking apparatus, and a host of others, which must be left for another time, but should be borne in mind when visualizing the overall picture.

\section{Rocket vehicles}

We have now discussed the performance requirements and various aspects of the technology. It is now appropriate to examine how these various ingredients are blended together into actual vehicles.

Both the Americans and Russians have now launched a vehicle with the same order of take-off thrust-the recent single American Saturn launching of $1,500,000 \mathrm{lb}$ thrust and the several Russian manned orbital launches with a vehicle with about two thirds of this thrust. It may well be that the later Russian tests in the Pacific used a vehicle with substantially larger thrust than this ready for the new generation of space work. It is, of course, relevant that whilst the Russians have been using this size of rocket for a year or two the Americans have fired only one Saturn with dummy upper stages. The Russians clearly have a lead of several years over the Americans in the operational use of such highthrust vehicles; the reason for this lead may well be traced back to the time after the last war when requirements were being written for the development of ballistic missiles; the Russians probably estimated the weight of their nuclear warheads to be very much greater than the weights anticipated by the Americans. Consequently, the Russians entered into a development programme of a far larger breed of rockets than the Americans. In the middle of the 1950s the possibility of using such rockets in the space role became a reality, and the Soviet Union found themselves with a rocket power capability far in excess of current Thor and Atlas American ballistic missiles. They have certainly exploited this to the full, and with the added weight in hand have not been driven 
to the crash programmes of miniaturization, with attendant initial development unreliabilities, which have undoubtedly contributed to some of the American problems in mounting their missions. The Americans are, of course, quite capable of catching up in this respect, although development times, costs, and manpower requirements are so great that several years must elapse before the new test facilities and rockets become available-always supposing both sides can support such necessary levels of expenditure. So little is known of the Russian rocket technology associated with their flights, that consideration of their achievements must wait until we deal with the applications.

From the American point of view however, Fig. 5 shows the "building bricks" that the Americans have used so far with their boosters and upper stages to achieve various rocket combinations which may be familiar to you. Some idea of the
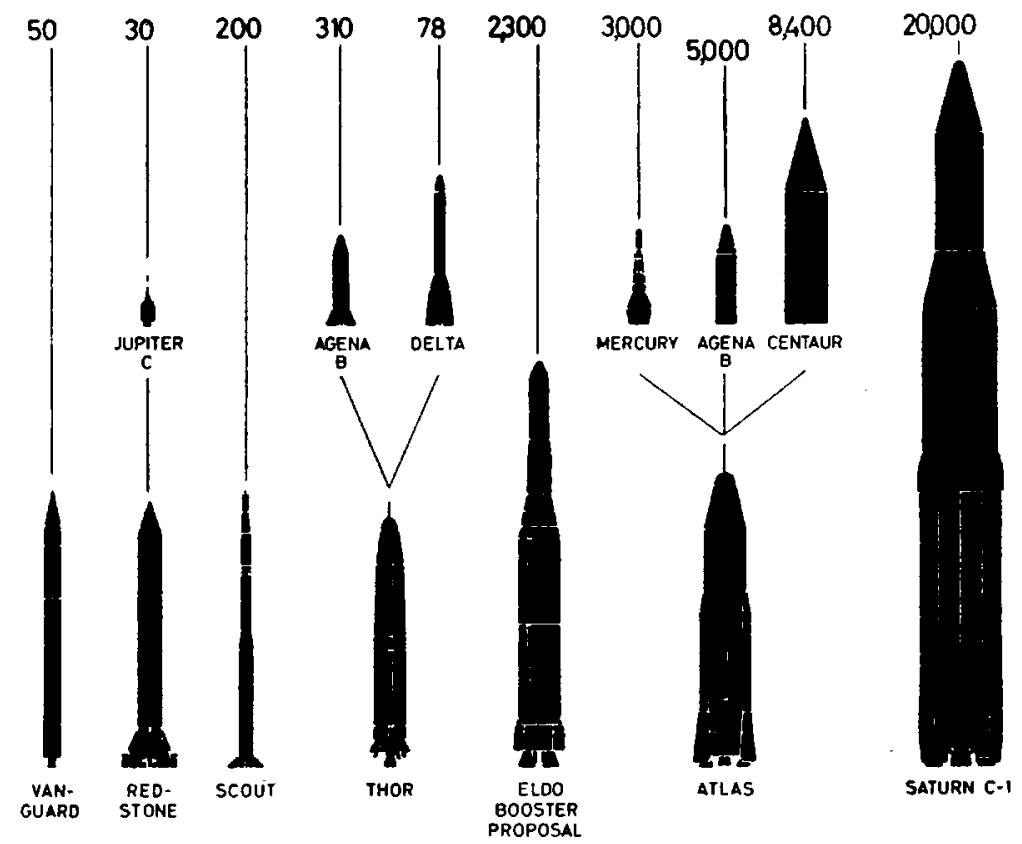

Fig. 5.-AMERICAN AND EUROPEAN SPACE ROCKETS

payload capability for placing equipment into the nominal low circular orbit (still earth conditions) is shown against each combination. Fig. 19 is a photograph of the recent Saturn C1 during assembly. None of these vehicles shown are adequate for providing a direct flight to the moon and return with a manned capsule, even though the Saturn development (C5 version) will be capable of placing 100 tons on a circular orbit 300 miles high. To achieve these deep space missions a technique called "orbital rendezvous and assembly" may well be used. This technique involves firing into a parking orbit around the earth, a succession of vehicles which then rendezvous with each other; some of the payloads carry fuel, and one is the manned spacecraft; after rendezvous, the components are assembled. The combined vehicle is then accelerated from its 
parking orbit to escape velocity and into the interplanetary transfei orbit to its destination. Such a technique may sound far-fetched but the Americans plan to begin on rendezvous technique experiments with the two-man Gemini capsule in 1964. This application will have civil as well as military implications.

It is appropriate to mention where European rocket proposals fit in to this picture. The French are working on a space rocket called Diamant in parallel with the Blue Streak programme. It is a three-stage rocket, the first stage using nitric acid and terebenthine, the second and third stages using solid propellant. It has a modest payload capability being between 50 and 80 kilogrammes into (for example) an elliptic orbit of perigee 250 miles, apogee 800 miles. It is a national project sponsored entirely by the French and the development is well advanced. Later versions of Diamant will have increased payloads of up to $330 \mathrm{~kg}$. The European Launcher Development Organization (ELDO) proposes a rocket based on the British Blue Streak, and which will be capable of placing in the first instance a payload of about a ton into the 300-mile circular orbit. The rocket shown in Fig. 20 will consist of three stages; the British Blue Streak ex-military rocket is the first stage, the second is a new French one using nitrogen tetroxide and unsymmetrical dimethyl hydrazine as the propellants, feeding a single gimballing thrust chamber of some 25 tons thrust; the third stage to be developed and built by the Germans. Blue Streak itself uses two rocket engines each with a thrust of $150,000 \mathrm{lb}$ and burns liquid oxygen and kerosene as propellants. Fig. 21 is a photograph showing the vehicle in its handling frame at the de Havilland Assembly factory at Stevenage, with the two thrust chambers and various other equipment located in the propulsion bay. Whilst it is of a modest size compared with the largest American and Russian vehicles currently in use, it will nevertheless provide a very adequate payload capability for a variety of missions which the European countries have in mind.

At this point it should be emphasized that it is vital that anyone who contemplates conducting research, civil, or military activity in space, must gain experience in the development of their own rocket-launching vehicles; in many instances the vehicle requirement must be tailored to fit the particular mission, and the whole process of launching it is so lengthy and complex, that unless the provision of the vehicle is under the control of the sponsor of the experiment the whole exercise can be of uncertain value and time scale. Quite apart from this there are a great number of indirect advantages that one gains from developing the rockets. In our 5 years of experience on Blue Streak in Britain, this has been forcibly brought to light, and within de Havilland it has led to the creation of separate divisions of work to direct these new techniques to industrial channels. In America the general rate of progress of engineering and technology is accelerating very rapidly as a result of the broadening of knowledge and improvement of techniques stimulated by this work. Some people might argue that these benefits are not as extensive as might be implied from these remarks. The fact remains that they are there, and cannot be ignored even though the degree of application may be difficult to assess.

\section{Spacecraft}

The applications of spacecraft fall into three main categories; scientific research, civil, and military use; it is proposed to deal with these in turn. 


\section{SCIENTIFIC RESEARCH}

This is the most obvious, and the first, application of our new-found ability, and an application which will stay with us for all time, because there is an unlimited fund of knowledge in the universe which will never be fully explored. Scientists of the world have learnt a vast amount already about the earth, its surroundings, and the solar system, since the end of 1957. The world is familiar with certain of those discoveries such as the radiation belts around the world (Fig. 22) called in America the "Van Allen" radiation belts and in Russia belts of another name! (Krassovsky and Chudakov). We now know the Moon has no appreciable magnetic field, and we have seen photographs of its reverse side. Very many other more fundamental scientific facts of the universe are already available to us.

Within a couple of months* the first satellite containing British built instrumentation will be fired into orbit by the Americans on a Thor Delta vehicle. This satellite, designated UK1, will be followed next year by UK2; each will contain a few different experiments.

Of American research satellites, some of the most interesting are the Ranger series designed to progressively approach the moon to learn more of the lunar characteristics. The first Ranger was recently sent into high elliptic orbit on a collision course with the moon, it did not unfortunately impact as planned but later versions, "Rangers" and then "Surveyors" will carry out a soft landing on the moon, after which instruments will transmit back information on lunar characteristics. A further series, called Prospectors, will then soft-land on the moon and be equipped with apparatus enabling them to move around in a more extensive examination.

In August, 1962, the relative positions of the earth and Venus in their orbits around the sun, will be such that reasonably low energy will be required for the transfer orbit between the two planets; there will probably therefore be an attempt by an Atlas Agena B vehicle to establish a payload in the vicinity of Venus (possibly with an injection into Venus orbit) and undoubtedly the Russians have the same thing in mind. The Russians too can be expected to make further investigations of the moon in the near future, with the almost certain ability to soft-land a package of instrumentation on the surface. Whether they will attempt in 1962 the more ambitious feat of depositing a package which can then be remotely moved around on the surface of the moon will remain to be seen, but I think we can rely with certainty on this year reducing considerably the mystery which has always surrounded the moon, our nearest heavenly body.

On the subject of scientific research it should be remembered that the European Space Research Organization (ESRO) is about to become formally established; this organization will create two centres of activity, one is to be a technical centre housing some 800 people of which 300 will be fully qualified scientists. This team will co-ordinate the construction of scientific research satellites and make arrangements for these satellites and space probes to be launched into their appropriate orbits. The second centre is to be a Data Centre which will be responsible for processing the information from satellites and co-ordinating the extensive network of monitoring and recording stations around the world associated with such experiments. ESRO will, therefore, be a most important

* The lecture was delivered on 13 February, 1962. 
organization covering scientific research interests of 12 European nations. Clearly it will be a very important user for the European Launcher Development Organization's launching vehicles.

Our Canadian colleagues are engaged in space research, and at present Canada is putting the finishing touches to the S27 satellite, the Top Side Sounder, which has been entirely constructed within Canada and will be fired shortly by a Thor Delta rocket provided by the National Aeronautics and Space Administration (NASA) of America. The satellite will measure certain phenomena associated with the top side of the ionosphere. This piece of scientific research is of particular interest to Canada in view of her nearness to the magnetic pole and her need for extensive radio-communication facilities within the continent.

The development of this satellite has produced certain ingenious devices, one of which (Fig. 23) is an extendable antenna developed by de Havilland, Canada, each unit weighing only a few pounds and yet capable of providing a rigid tube of 1 inch diameter formed by unwinding a preformed strip of metal from a drum. In addition to its use as an antenna, it is being tested as a gravity-gradient attitude-stabilization device, and in this capacity has already been launched into orbit in the American Traac satellite. Developments of this device are being considered for use in other satellites, with extensions of up to $500 \mathrm{ft}$.

This example shows the importance of ingenious methods of erecting equipment on satellites for a variety of purposes. Few space fiction writers of the past could have conjured up more curious and complicated spacecraft than many of those already fired and working successfully in orbit. The absence of air and of an acceleration field gives plenty of freedom to the designer in this respect, even though the hazards of radiation fields, hard vacuum conditions, high temperature gradients, and weightlessness cause new and severe problems in other respects.

The solution of many problems of space research can be envisaged by the use of automatic equipment remotely controlled from earth. Although the time has already been reached when the natural adventurous spirit of man and his desire to progress have led to men travelling in spacecraft in orbit round our earth, one may argue that he is not fundamentally necessary for research, and that "man in space"is premature. However, research discoveries in the past have frequently been side products of the primary objective of an experiment, noticed only by the broad intelligence of the human brain. So it will be with space research, and whilst at this stage I do not think that this reasoning alone justifies our present European programmes including a man-in-space project, man will undoubtedly contribute in good time to scientific discoveries in space. $\mathrm{He}$ may even be required as a service engineer.

The Americans plan to follow their present Mercury flights with two-man Gemini orbital craft, as a prelude to the Apollo programme designed to land a capsule containing three men safely on the moon between 1967 and 1970 and returning them to earth. These projects are based on a research requirement even though the motivation for such a programme at the moment undoubtedly stems from the challenge presented by the Russians in their dramatic successes so far with human space flight. Before the Apollo capsule is placed in orbit by the Saturn vehicle however, the Americans will have gained further experience of manned flight by the use of the winged Dyna Soar space craft; this will be launched probably in 1963 or 1964 by a modified Titan 2 two-stage rocket. Dyna Soar will enable the pilot to influence his re-entry path into the atmosphere 
by the use of aerodynamic controls, compared with the present techniques which depend on the ballistic re-entry of a vehicle. Fig. 6 illustrates the various trajectories that may be envisaged in this respect in the re-entry phase.

Already there are extensive plans and indeed an astounding amount of experimental and even development work in the U.S.A., on the problems of establishing suitable bases on the moon in which man can live and work. At the American Rocket Society Space Flight Report to the Nation Exhibition in New York last October there were many examples of these on display and many papers were read on such extraterrestrial living quarters. We must remember that these lunar facilities are only 6 to 8 years away and therefore no longer the subject of idle speculation. Whether the cost of establishing these facilities in that time scale is logical from a financial point of view, is a matter on which I would not wish to offer views this evening; however progress is not always logical and there is little doubt in my mind that we shall see these events happen this decade.

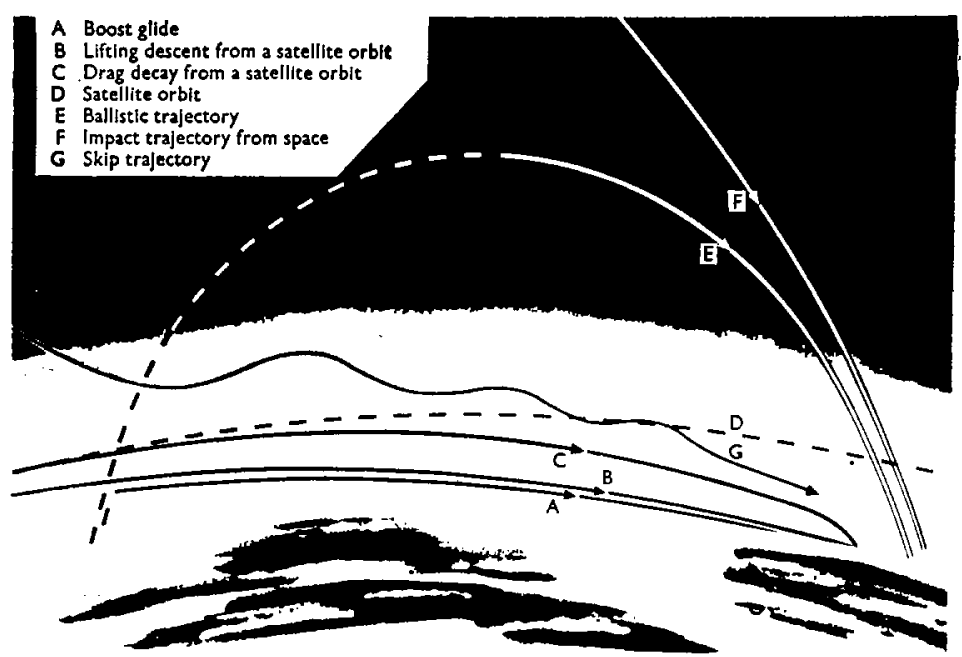

FIG. 6.-DIAGRAM OF VARTOUS TYPES OF ENTRY TRAJECTORY INTO THE ATMOSPHERE

I suggest however for the moment we leave our men on the moon, and come back closer to earth, to examine the hard commercial facts of life and how we may expect to pay our way.

\section{Civil applications}

This heading covers those direct applications of space which can be turned to civil or commercial use by the direct utilization of satellites in orbit. In this family are the well-known triplets navigation, meteorological and communication systems.

\section{NAVIGATION SYSTEMS}

The concept is simply to replace the stars as an aid to navigation, by an earth satellite the passage of which is precisely known in time and position, and can be 
measured in all weather conditions at any point of the world, thus enabling (after suitable computation) the position of the observer to be determined with great accuracy. The American Transit project (Fig. 24) is just such a system developed for the American Navy, to be used at an early stage in assisting Polaris-carrying submarines to determine their position accurately. This may seem to be a contradiction, of the civil heading, but although prompted by military requirement the project does however hold the prospect of civil and commercial application, since the techniques can be extended to merchant ships as well as naval ships all round the world. The Transit system makes use of a tape recorder and transponder in the satellite, the orbit of which is measured accurately at regular intervals by a master tracking station, and a command system feeds the precise information of the orbit into the tape recorder. During transit around the world, the satellite transmits a signal, coded to contain its orbital information. The receiving station on the ground is equipped with omni-directional antennae (a large directional type of antenna normally associated with tracking satellites is not required in this instance) and as a result of receiving instructions from the satellite signals on its trajectory, and by measuring the Doppler shifts of the satellite transmission over a short period of time during its passage across the sky, a simple computer network can then determine the relationship of the ground station to the satellite orbit; hence the position is known. Accuracies of a few hundred yards are expected, and with the evolution of techniques, even greater accuracies can be anticipated. It might be argued that this sort of accuracy for merchant ships is generally unnecessary on high seas and adequate accuracy can be determined in any case by orthodox means; moreover in coastal waters where such accuracy would help, it is already available in more positive ways, by the use of marine radar. This may well be so, and at first probably only large liners will install the equipment, but provided the cost can be kept at the reasonable level of a few thousand pounds, it is inevitable that such equipment will ultimately be installed more widely in ships.

Installation of the necessary receiving and computing equipment in aircraft is somewhat further off, but there is no fundamental reason why this should not be achieved and it would seem to be just a question of time.

I shall make no attempt here to discuss the commercial or economic aspects of the system. The Americans will soon however have a fully operational system experience based on Transit, and their results will undoubtedly influence to a large degree, the type of system which the world may expect to use in years to come.

\section{METEOROLOGICAL SATELLITES}

Perhaps this category of satellite application is as well recognized as any other. The principle is easily understood and consists of mounting television cameras in the satellite pointing down towards the earth. The provision of two or more cameras with different fields of view enables the cloud cover of the earth to be observed by the television signals transmitted to suitable ground receiving stations; the information is then analysed and leads to accurate and rapid world weather forecasting. It is a matter of interest that Tiros 1 (Fig. 25) and 2 in the early parts of their lives, produced more than 23,000 photographs at such a rate that the system of analysis and distribution of the information on the ground, was completely overwhelmed, and the project had to be slowed down somewhat, 


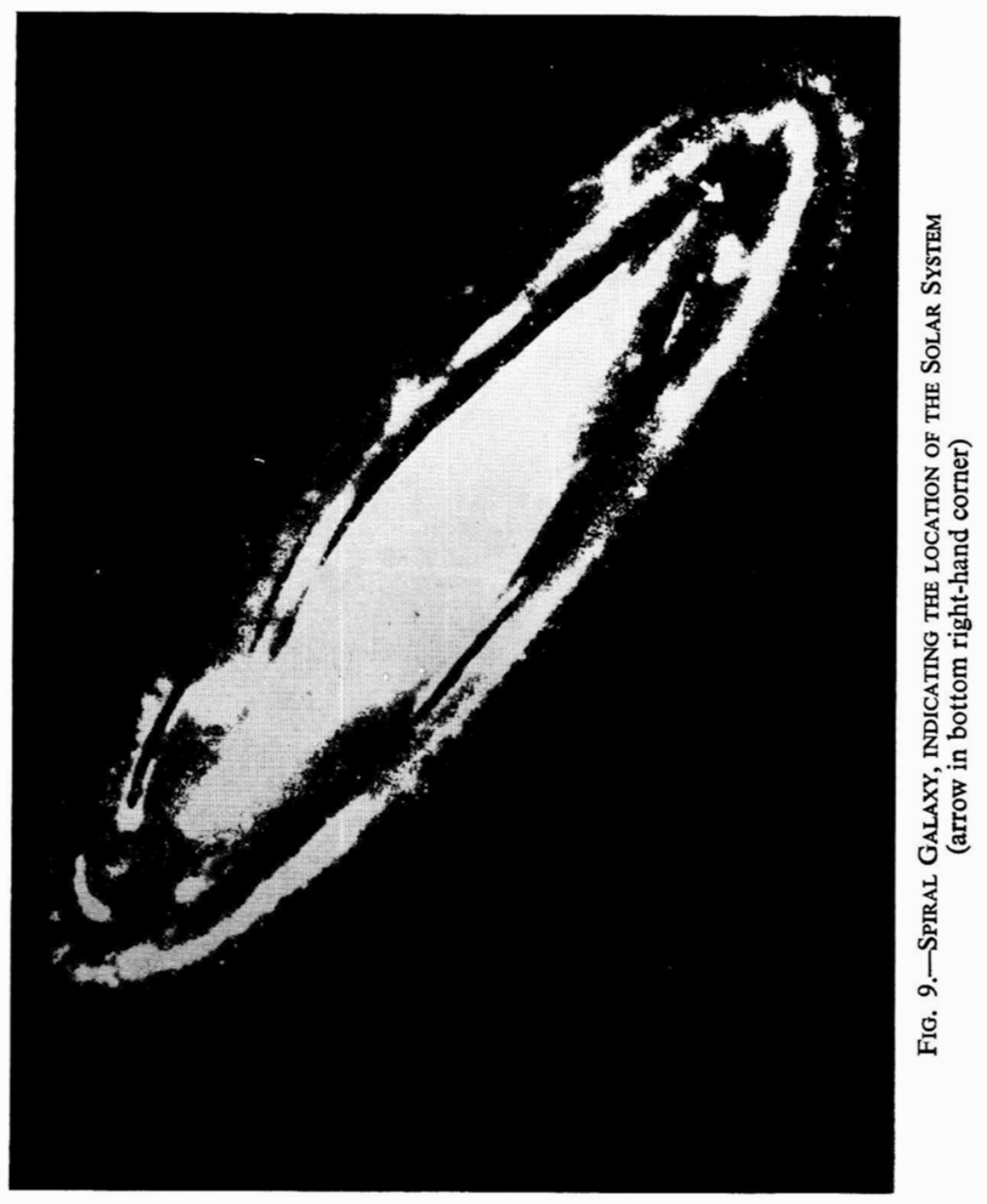




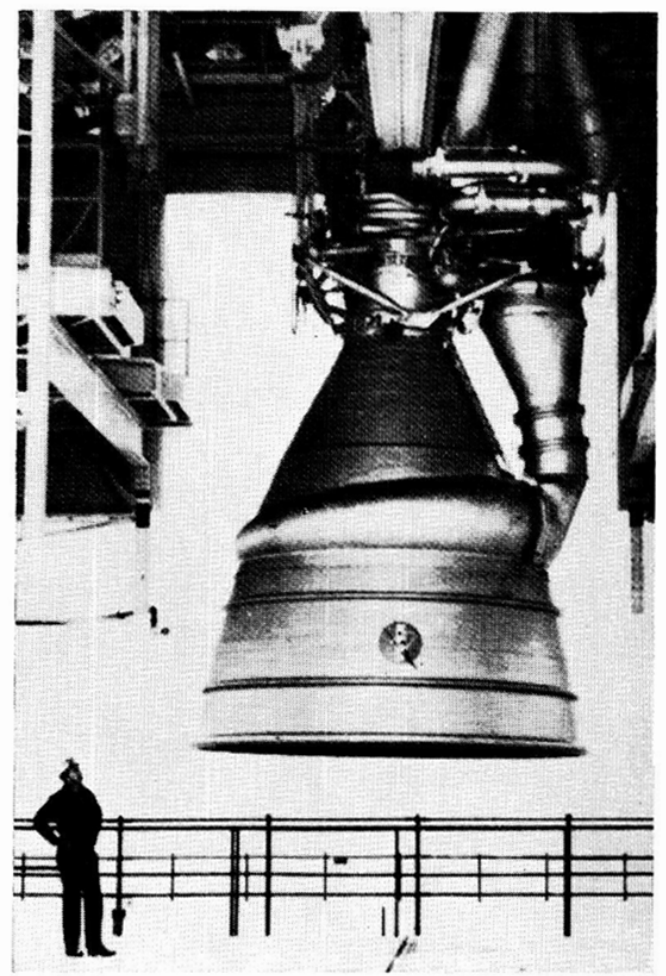

Fig. 10.-F-1 ROCKET ENGINE COMBUSTION CHAMBER, DIAMETER OF BASE 10 FT (NORTH AMERICAN AVIATION COMPANY) 


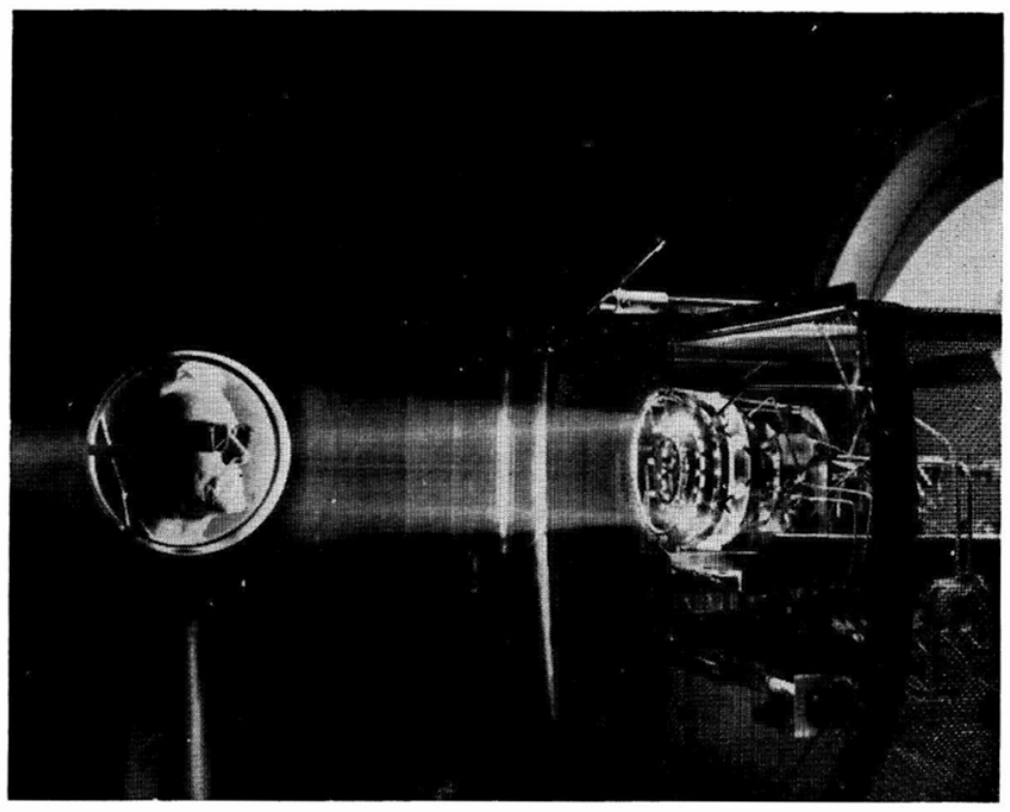

FIG. 11.-HUGHES ION ELECTRIC ROCKET UNDER TEST

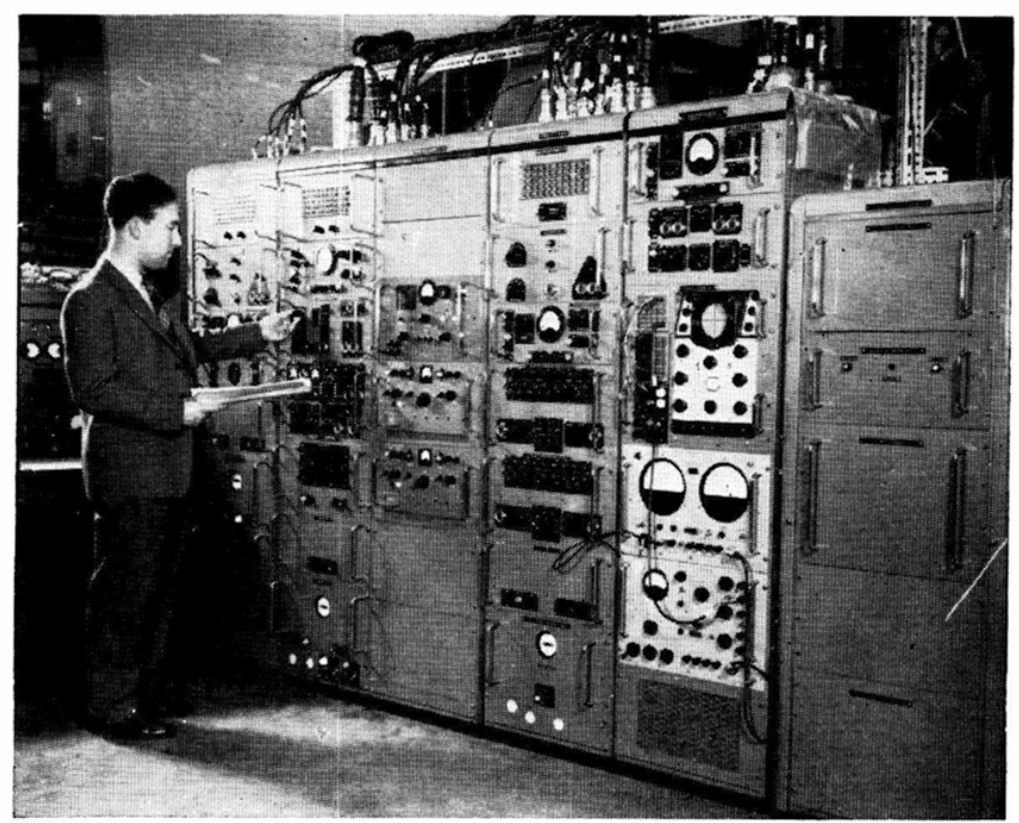

Fig. 12.-Part of de Havilland Blue Streak check-out equipment $28^{*}$

Downloaded by [] on [26/04/23]. Copyright @ ICE Publishing, all rights reserved. 


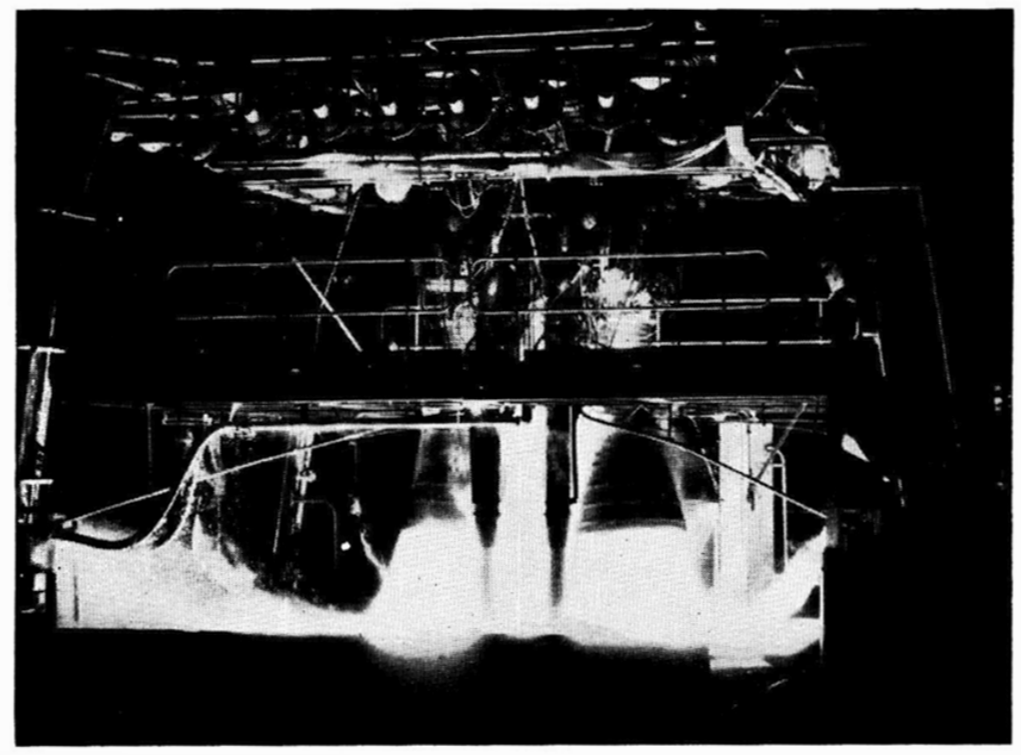

Fig. 13.-Twin Rolls Royce Rocket engine, test-Firing at the Rocket Research Establishment, Spadeadam, CUmberland

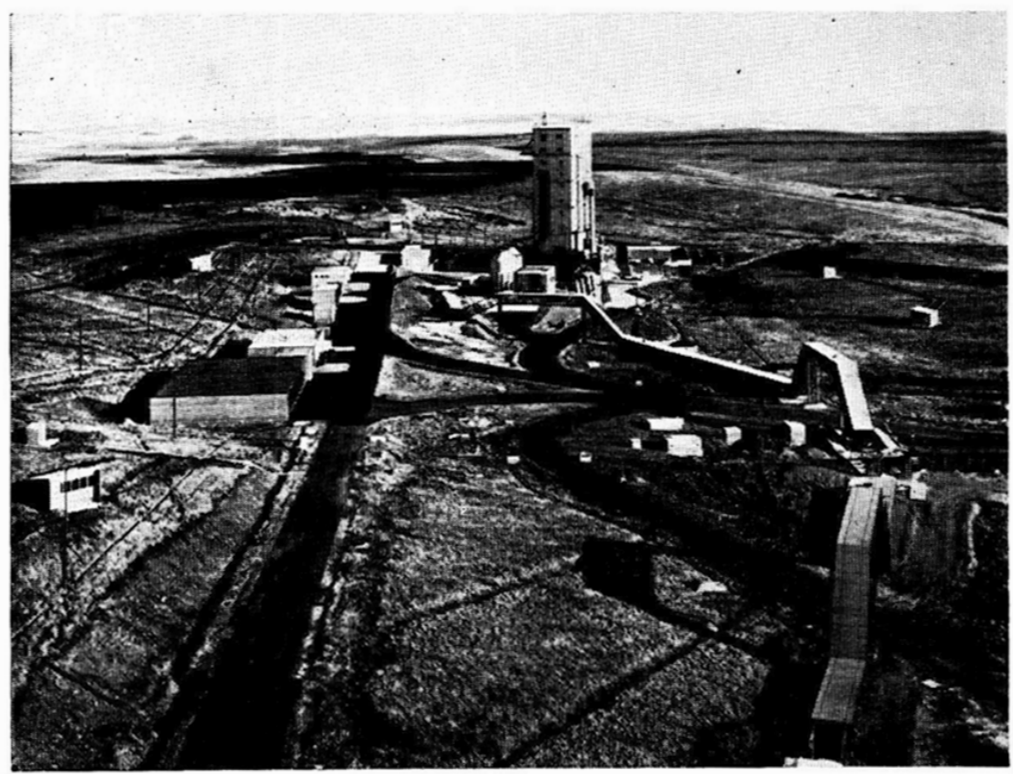

Fig. 14.-De Havilland Blue Streak test stand at the Rocket Research Establishment, SPADEADAM 


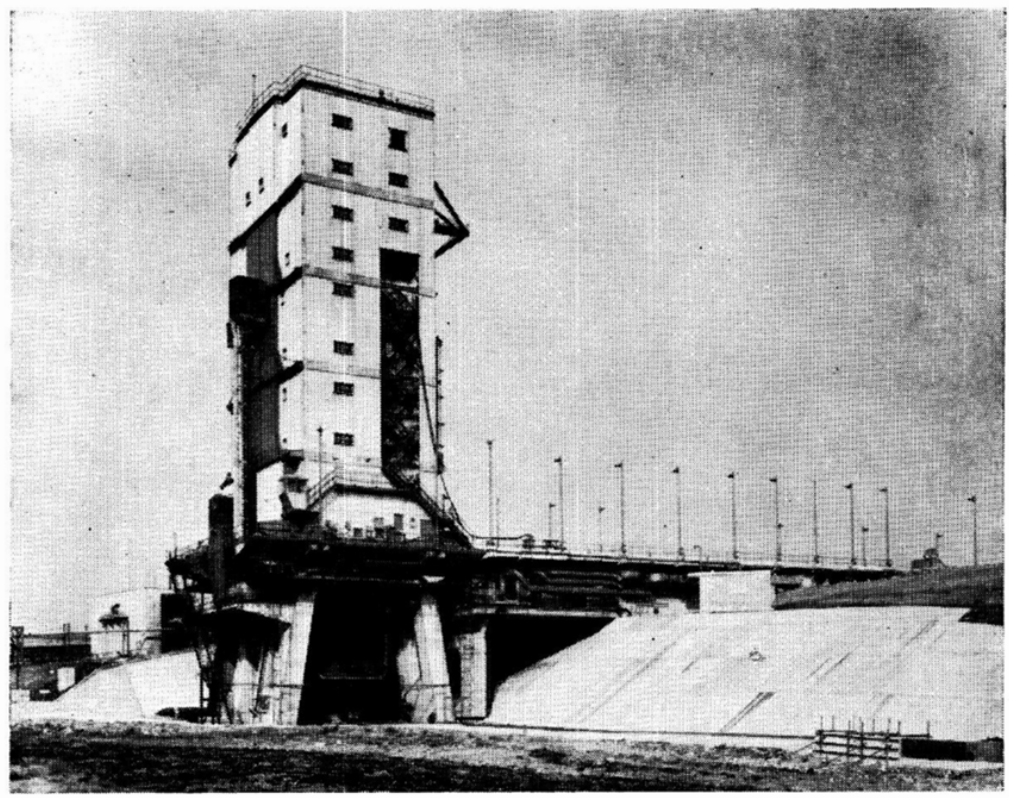

Fig. 15.-De Havilland Blue Streak test stand at the Rocket Research ESTABLISHMENT, SPADEADAM

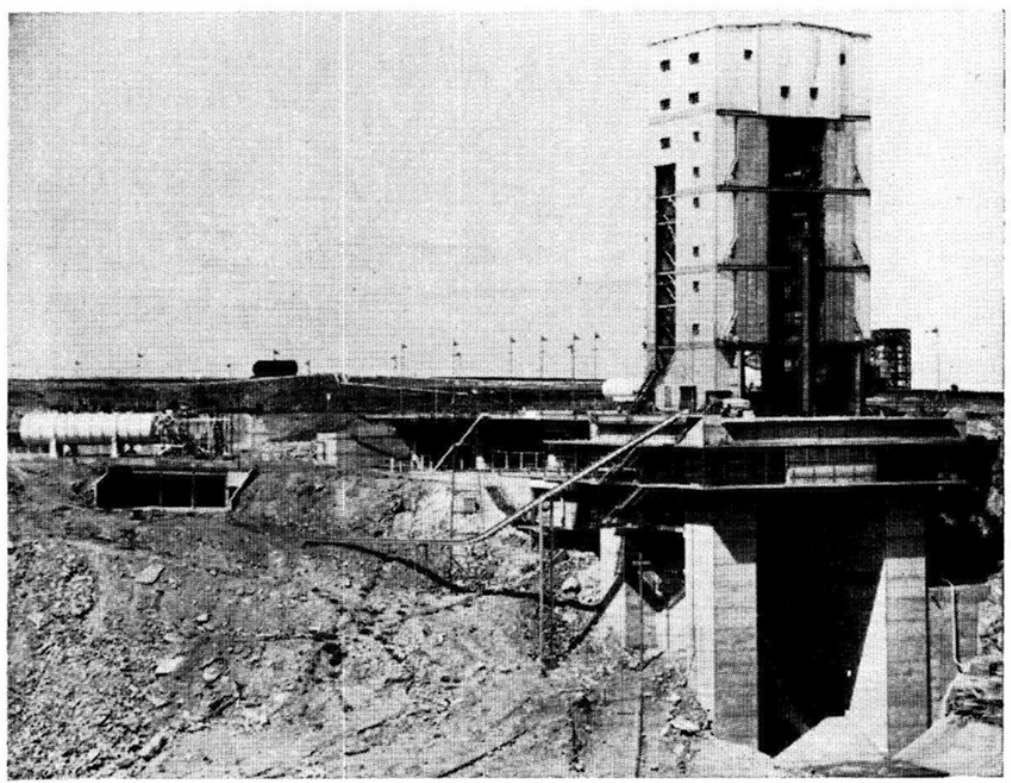

Fig. 16.-Blue Streak launching pad at Woomera, Australia 


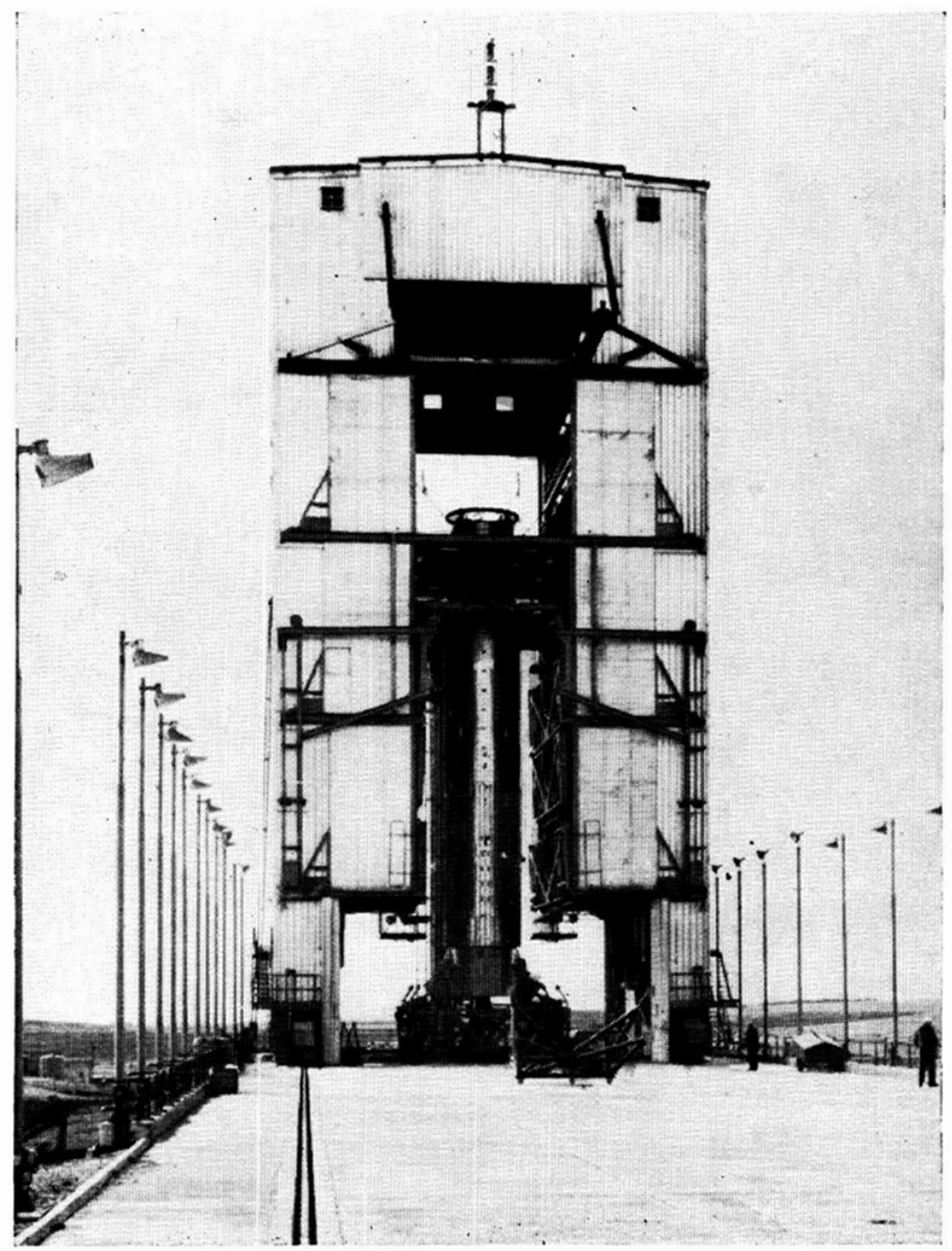

Fig. 17.-Servicing tower and Blue Streak at Spadeadam 


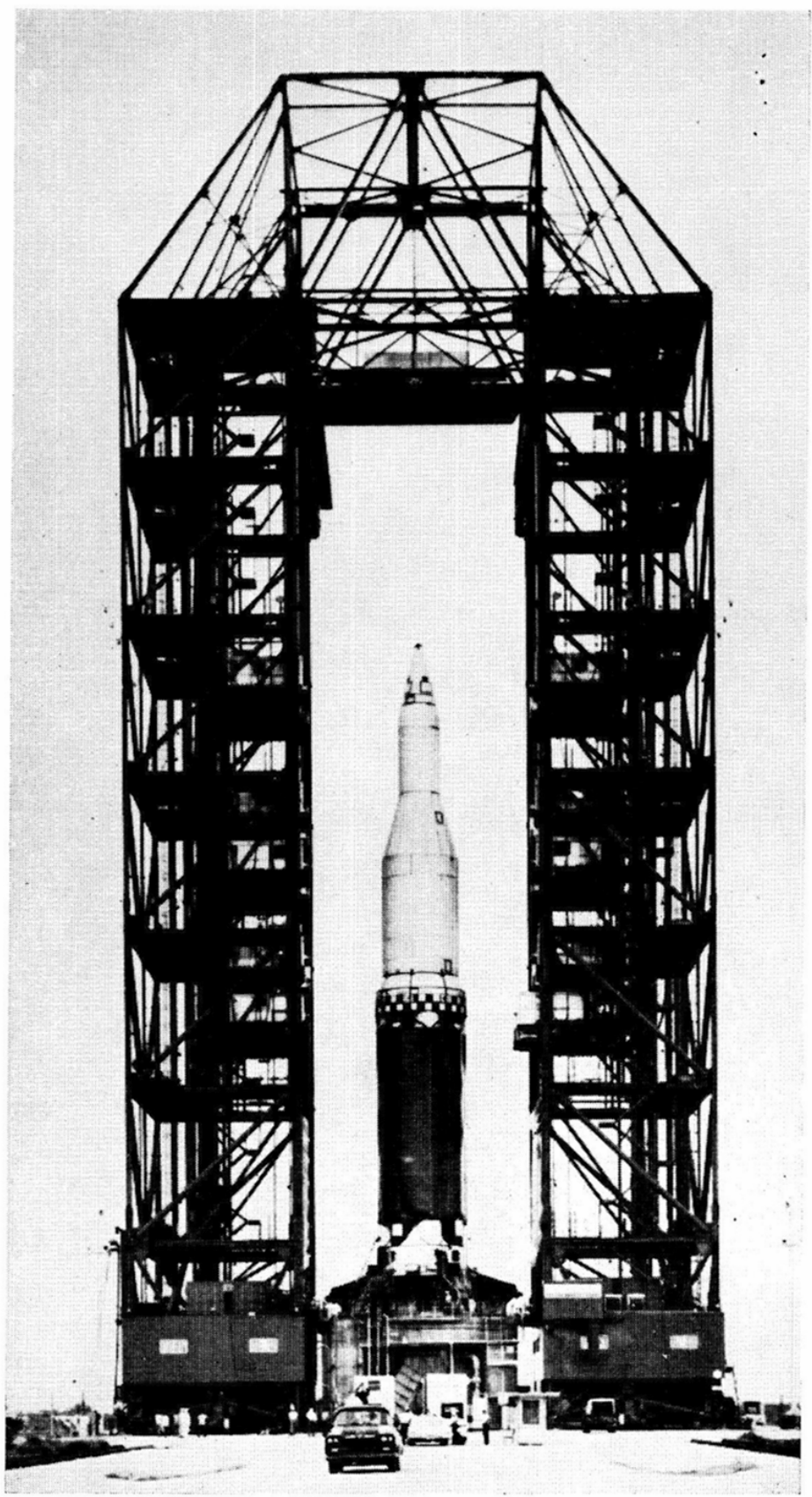

Fig. 18.-SATURN C-1 ROCKET IN ITS SERVICING TOWER ON THE LAUNCHING PAD AT Cape Canaveral, Florida 


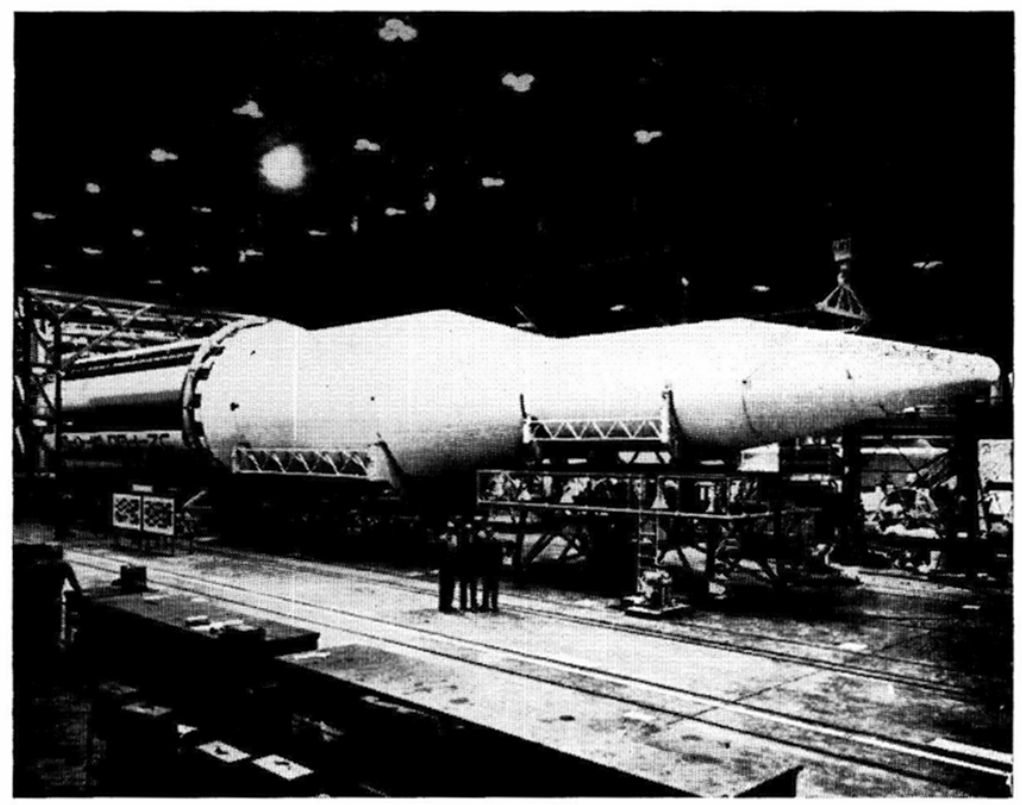

Fig. 19.-SATURN C-1 ROCKET DURING ASSEMBLY

Downloaded by [] on [26/04/23]. Copyright @ ICE Publishing, all rights reserved. 


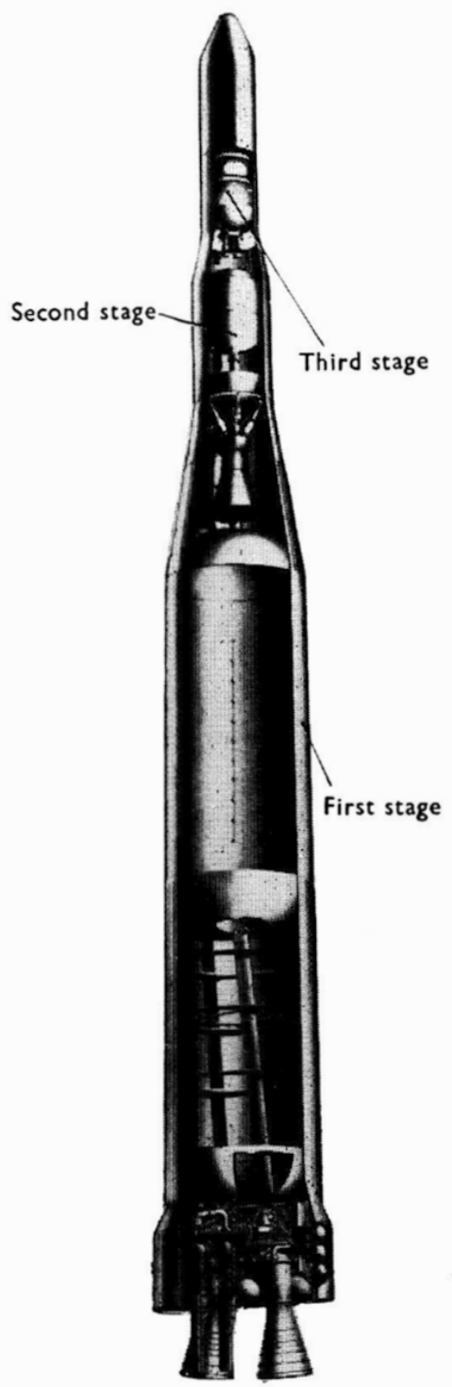

Fig. 20.-Proposed European Space rocket Based on Blue Streak

Downloaded by [] on [26/04/23]. Copyright @ ICE Publishing, all rights reserved. 


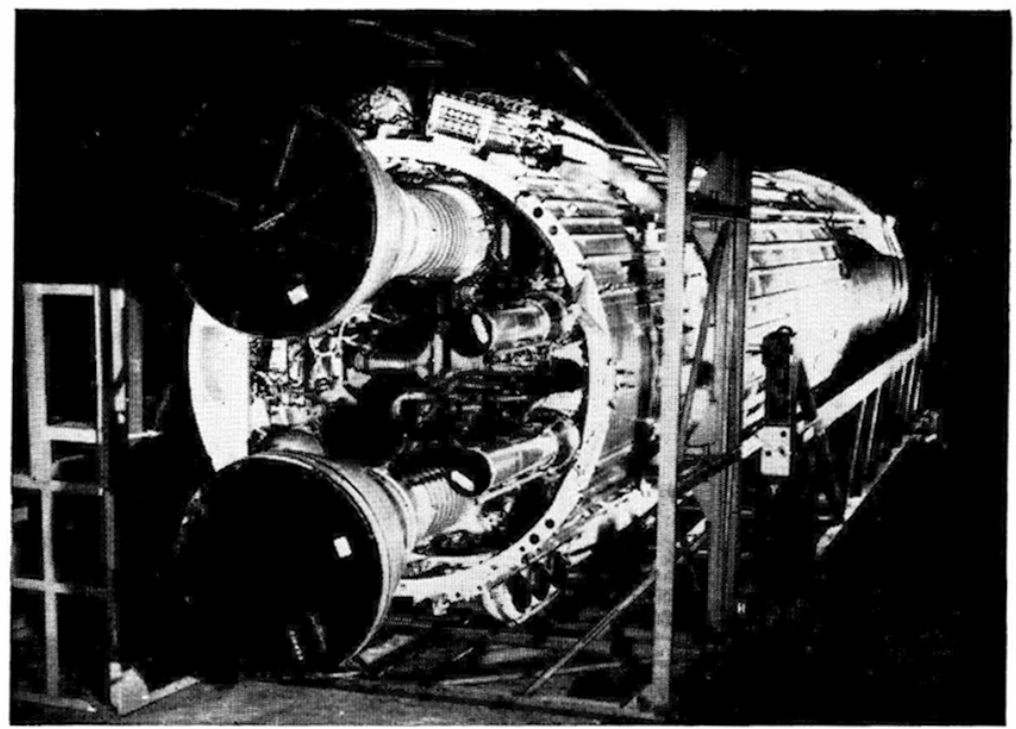

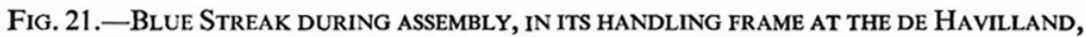
STEVENAGE FACTORY

Fig. 22.-The VAN Allen RAdiation FieldS 


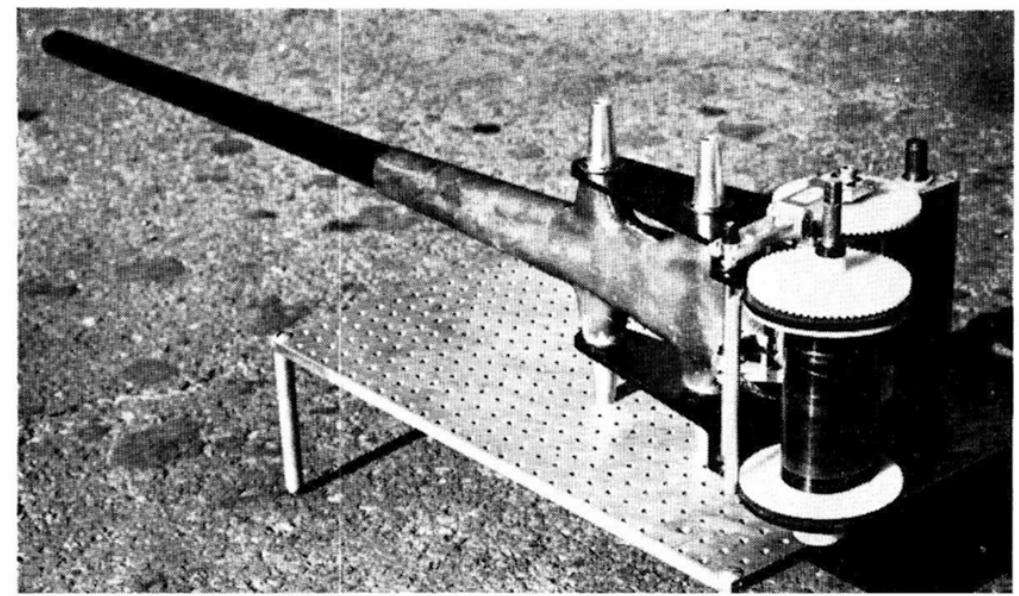

Fig. 23.-Extendable satellite antenna, made by de Havilland, Canada

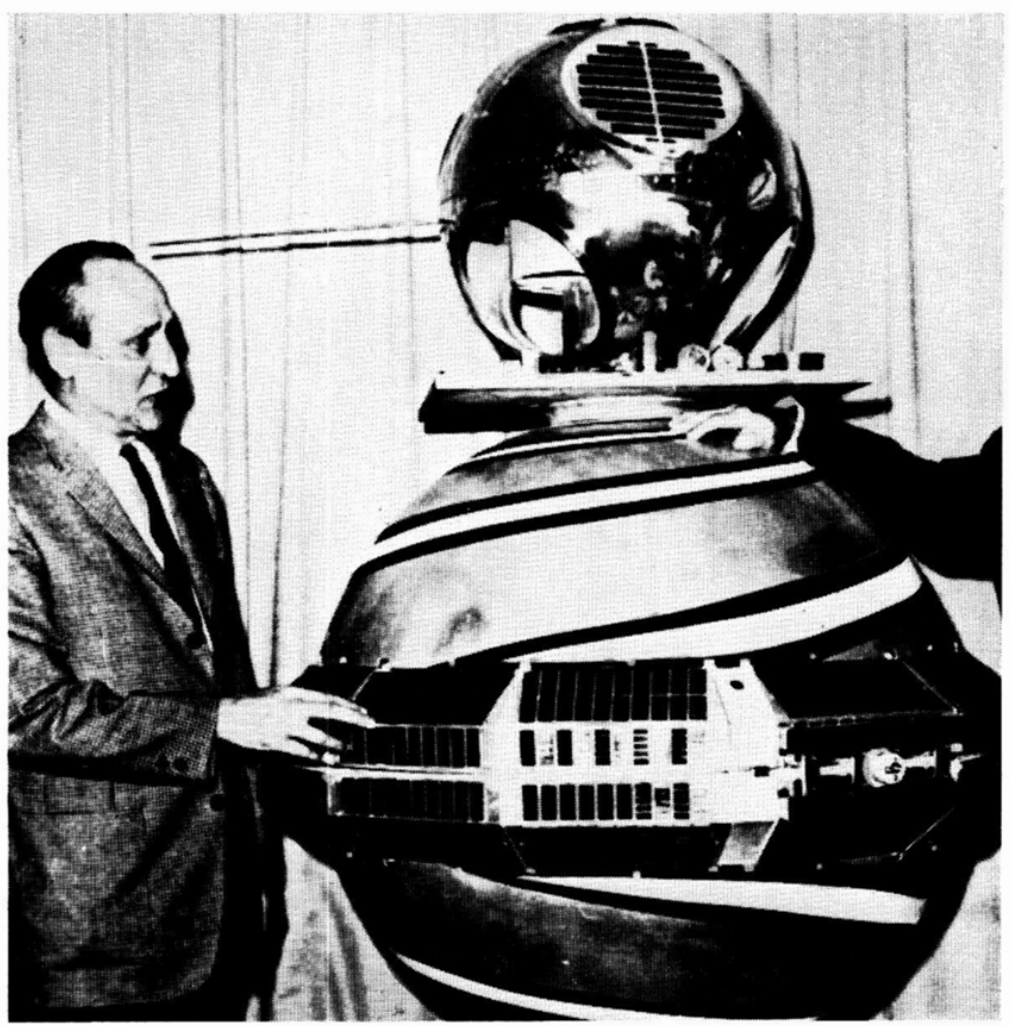

Fig. 24.-Transit 2-A Satellite and SMaller SATEllite, N.R.L. 


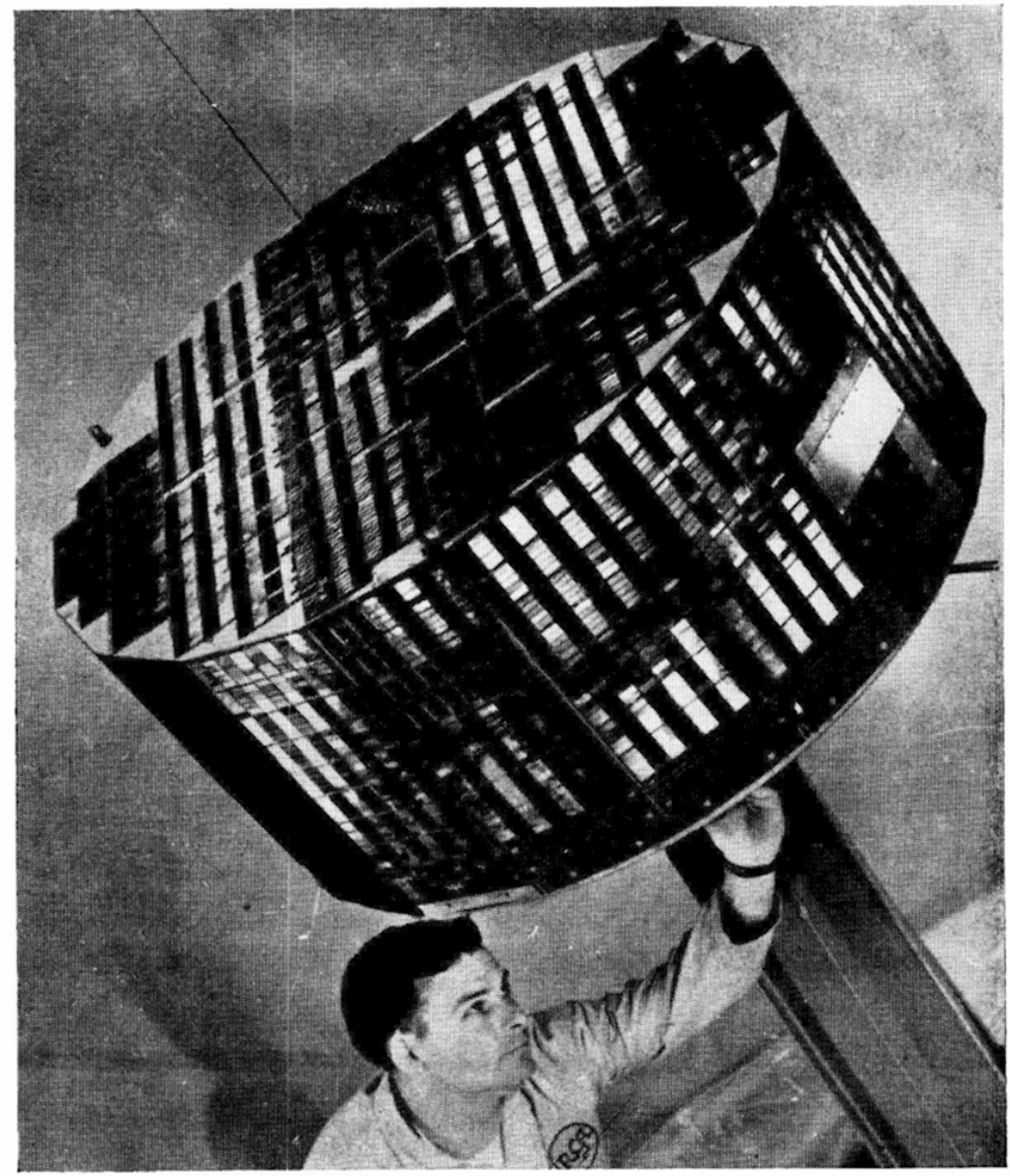

FIG. 25.-TiRos-1 WEATHER OBSERVATION SATELLITE 
until suitable apparatus and techniques were developed to process the data automatically.

This lack of anticipation of necessary ground-support equipment is a valuable object lesson, which should be applied to many aspects of space technologyand $I$ am sure in many other fields as well. Indeed in ballistic vehicle and space programmes of the nature we are discussing, the ground support and range equipment is far more expensive and costly than the vehicles themselves.

The latest version of the satellite Tiros 3 was launched on July 12, 1961 into a near-circular orbit with an inclination of $47.8^{\circ}$ to the Equator; it carried two television cameras with wide- and narrow-angle lenses and undertook a new infra-red experiment to measure solar energy absorbed, reflected, and emitted by the earth. The project was very successful, although one of the two cameras failed following the 170th orbit on July 24, but the second camera, pressed into full-time service, performed very well and it is of interest that the satellite photographed many of the tropical storms during the 1961 hurricane season and is credited with discovering hurricane Esther. The Tiros satellite is also interesting because it has a magnetic orientation-control system which consists of a coil wound round a diameter of the spacecraft. The coil is intermittently activated by electrical power, derived from the nickel cadmium batteries which are in turn charged by 9,260 solar cells. Thus, on command, the magnetic field so produced would interact with the earth's magnetic field and thus alter the attitude of the satellite. The satellite shaped like a drum is some $42 \mathrm{in.} \mathrm{diameter,} 19 \mathrm{in}$. high and weighs $285 \mathrm{lb}$.

The U.S.A. have indicated that they will make available to the world the majority of the weather forecasting information derived from their Tiros satellites. It may well be that this service will be adequate to satisfy world interests, although in view of the complexity of the analysis and distribution problems, as well as the limitations of the orbits chosen and the ground stations suitable for receiving the data, it may be that another system (originating from this side of the Atlantic) would be justified in years to come. Whether or not we can view this application as a revenue-earning system remains to be seen. It is nevertheless a most exciting tool of meteorological science, from which much has already been learnt about the pattern of our weather. The experiments conducted so far by the Americans are already beginning to have a direct influence in the saving of life and money, by observing the formation and progress of hurricanes etc. In a few years' time I am sure we shall make use of this information from satellites almost as a matter of course.

\section{COMMUNICATION-SATELLITE SYSTEMS}

It is this work that I would rather like to emphasize this evening, because it represents a potential money-earner of great magnitude to the operating organization, and also represents the first direct use that the average citizen will make of satellite systems.

The limitations of orthodox radio communications caused by the uncertainties and variabilities of reflecting line-of-sight-limited radio signals off the world's ionosphere, are well known. Moreover the need to keep the frequency of such transmissions to relatively low values in order to make use of the reflecting characteristics of the ionosphere, leads to the present congestion of these lower frequency bandwidths. The principle of a communication satellite is quite straightforward-each satellite replaces the ionosphere, and provides a reliable, 
properly designed reflecting device, acting as a relay between line-of-sight transmissions from one ground station to the satellite and back to a further ground station and so on around the world. Various orbit altitudes for the satellites have been considered, the maximum of these being a circular orbit located in the plane of the equator at an altitude of 22,300 miles above the surface of the earth. - Fig. 7 shows a ring of 8 satellites at 8,000 miles and one at 22,300 miles above the equator. It is at this unique altitude (22,300 miles) that the satellites' period of revolution around the earth is exactly 24 hours, and with the orbit above the equator, clearly the satellite will remain over one location, on the equator. Viewed from the earth it is therefore stationary, and is referred to as a "stationary" or "synchronous" satellite system.

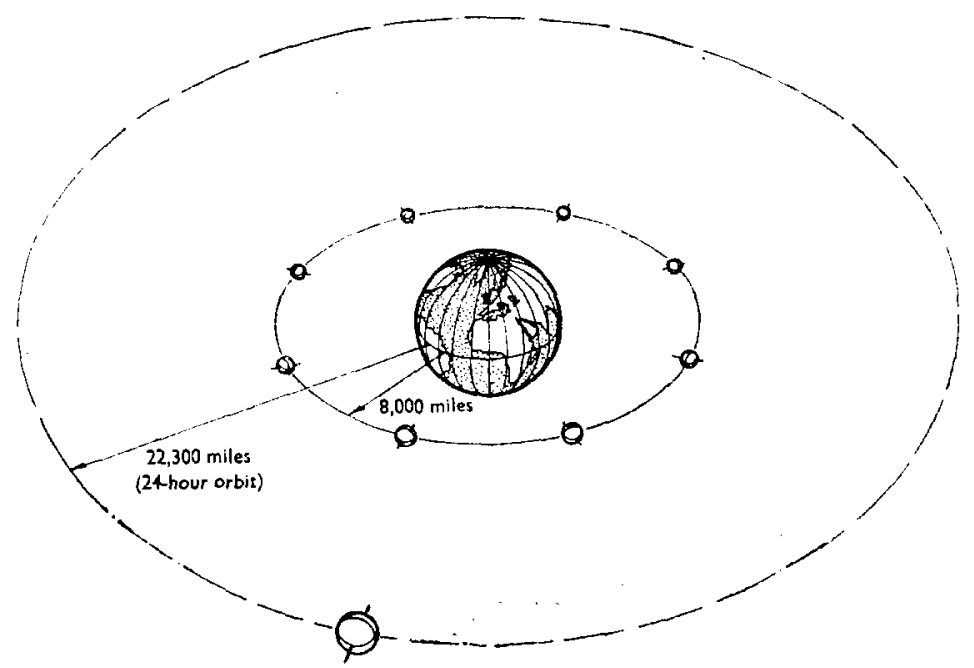

FIG. 7.-EXAMPLES OF ORBITS OF COMMUNICATION SATELLITES

Both passive and active satellites systems are being considered and indeed the world is very familiar with the existence of the Echo satellite which was first launched on 12 August, 1960. This was in a low circular orbit at an altitude of about 1,000 miles, and was a 100-ft diameter aluminium-coated mylar plastic sphere, which reflected ground transmissions back to the earth in a manner just described. It was very successful, and indeed is still in orbit, and can still be seen. With time the satellite has become very wrinkled, mainly due to loss of pressure inside, caused by micro-meteorite impact. It is of interest too that whilst the orbit was nearly circular at the time of launch, the pressure of light from the sun acting over the last 18 months has now changed the orbit to an ellipse the apogee (highest point) of which is 1,334 miles and the lowest point some 619 miles, a very significant change and a powerful demonstration of the cumulative effect of the low photon pressures that we receive at this distance from the sun.

It is my belief that this passive satellite system has limited application, even though it is a very interesting medium for research. This is mainly caused by the lack of amplification in the satellite which therefore demands so much power 
from the ground stations to enable a signal of suitable strength to be received back at the ground antenna. Thus the satellites must be kept fairly low and therefore fairly numerous. Undoubtedly such a satellite has inherent reliability once the technique of maintaining the shape of the satellite indefinitely is achieved. New techniques may become available but at present $I$ believe the active satellite to have far wider use. Before leaving passive satellites, however, it is of interest to mention our natural moon, from which radio waves have been bounced for the last few years between different radio stations on the ground; The U.S. Navy use the moon operationally to reflect signals between their headquarters on the east coast of U.S.A. and their station at Hawaii; this service has been in regular use for some years, and transmits telephone, telegraph, and facsimile material.

Let us take up the story again with the satellite at 22,300 miles. One advantage of its stationary location with respect to the earth, is that the ground antenna working with it, can be fixed, and need not be steerable, therefore avoiding the complexities and cost normally associated with satellite tracking arrays. There is however one fundamental difficulty - a typical path length from one ground station to another via such a satellite would be some 48,000 miles, and this would lead to a time delay of at least some 250 milliseconds between ground stations, often twice this. Such a delay would normally be accompanied by an echo caused by 2- and 4-wire junctions in the existing telephone network ground circuits. A combination of delay and echo causes significant inconvenience to two people carrying out a telephone conversation. The degree of this inconvenience is a matter of controversy-but at least it is fairly widely accepted now, that the echo can be suppressed, and we are then left with the question of delay. A considerable amount of experimental work has been done by creating artificial delays into subscriber networks, and I think there is a trend towards an acceptance of a delay of this order. Nevertheless, much more experience is necessary before decisions can be reached. The same problem of delay does not of course matter for television data, or telegraph transmissions, and for these reasons there is no doubt in my mind that we shall use satellites at this altitude in years to come. Equally I think it unlikely that the first operation systems in the world will be at this altitude and that lower orbits using more satellites, will be used. It can be seen that three satellites placed round the world at this 22,300 miles altitude, could of course cover most of the areas of civilization, whereas at lower orbital heights more satellites would be needed. In the plane of the equator, at about $8,000-9,000$ miles altitude, between 8 and 12 satellites equally spaced around the orbit would be needed to provide 24-hour coverage of the civilized parts of the world up to a latitude of approximately $60^{\circ}$. The precise number of satellites would depend on various telecommunication requirements-for example whether the Atlantic must be crossed in one hop or two, and what is the lowest angle of radio horizon that can be used for the ground antenna when tracking a satellite disappearing down below or rising above the horizon; at present a typical value for this is about $5^{\circ}$.

Once one has moved away from the 22,300 -mile orbit height (which is unique) the orbit need no longer be maintained above the equator, and the other extreme is to use polar orbits, that is to say with the plane passing through the north and south poles. There can also be inclined circles or ellipses, but it is not my intention here to go into a detailed analysis of these various systems. However, it is our opinion that a suitable system to provide a Commonwealth and world communication network, will consist of 8 to 10 satellites located at a circular 
altitude of approx. 8,000 nautical miles, each satellite keeping station in relation to the next one in the ring, and each to be attitude-stabilized with respect to the earth.

The British Space Development Company, formed nearly a year ago and now comprising 11 major industrial organizations in Britain in the field of aviation, electronics, television, nuclear power, etc., has, via its Technical Committee of which I have the honour to be Chairman, carried out extensive work on such a system, and it is hoped to publish our first-phase conclusions shortly. We can say however, that we believe we must develop such a system, and that it will be viable.

Britain has a tradition of leadership in world telecommunications, and unless we embark on such a system rapidly, we shall cease to retain our place in the world in this vital and lucrative market. The present cables which are being laid around the world will cost some $\mathfrak{£ 9 0}$ million and yet will have a capacity of only 80 channels. They will supply the needs of the countries adjacent to the cable for a few years to come, but can in no way compete in cost or potential coverage, with the satellite system.

In determining revenue we have looked for methods other than merely observing past trends (which can be most misleading). We have noted a relationship between the telecommunication costs and the turnover of various companies, over the years, and we have further determined that a similar relationship should exist on the national basis. Therefore an examination of world trade and its trends (which is known very well) gives an idea of the latent demands which there will be for communication facilities when facilities can be offered-as they can only be offered by a communication satellite system. Introduction of this "trade concept" creates enormous stimulus factors which may well lead to very much higher estimates than those that I have just referred to.

These two examples of the relationship between transatlantic telephone calls for 1961 across the Atlantic (Table 2) and the comparable relationship between

TABLe 2.-INTERCONTINENTAL CALLS, estimate FOR 1961

\begin{tabular}{|c|c|}
\hline Intra world excluding north transatlantic & $25 \%$ \\
\hline North transatlantic & $75 \%$ \\
\hline
\end{tabular}

world trade compared with the North Transatlantic (Table 3) gives some idea of the influence which we may see in this respect. We can of course expect too, that this will work favourably in reverse, and where communication facilities are provided, trade will be stimulated.

To summarize, those of us working closely on the problem are filled with the

TABLE 3.-DISTRIBUTION OF WORLD TRADE 1959, EXPORTS

\begin{tabular}{|c|c|c|c|}
\hline Intra world excluding north transatlantic & . & $£ 36,000$ million & $90 \%$ \\
\hline North transatlantic & . & f 4,000 million & $10 \%$ \\
\hline
\end{tabular}


great sense of urgency and awareness of the importance to our way of life, of the creation of such a new world system.

The programme for this work must be related to the programme of ELDO and the Blue Streak vehicle, but there seems no reason why the system should not become operational and revenue obtained from it between 1968 and 1970, depending on the rocket programme agreed.

This year 1962, will see three separate experiments with active communication satellites, two of which will be conducted across the Atlantic between America and Britain and other European countries. One of these will be Project Relay, in which the National Aeronatics and Space Administration in America will launch a small satellite built by R.C.A., to relay television, telephone, and telegraph signals experimentally between the Bell Telephone Laboratories' ground antenna at Rumford, Maine, and the General Post Office's station nearing completion at Goonhilly Downs in Cornwall. These experiments will throw very important light on the techniques and procedures which may well be incorporated in subsequent operational systems. In parallel with this, American Telephone and Telegraph Co. (Bell Telephone Labs particularly) are privately sponsoring, and paying for the project Telstar, in which another satellite will be placed into orbit by arrangement with NASA, from whom the launching rocket and facilities will be purchased. Thirdly the Hughes company in America have a contract for a project Syncom in which they will launch from Cape Canaveral a small satellite from a Thor Delta rocket into a 22,300-mile circular orbit inclined at $30^{\circ}$ to the equator-not a true stationary orbit, since when viewed from the equator, the satellite will appear to move north and south once a day. However it will examine for the first time the various problems and techniques which I have mentioned previously, associated with this orbit height. These three experiments will be of vital significance and will be conducted in parallel with more general research on techniques tested in other satellites.

1962 will therefore be a key year in the history of world telecommunications, and the recent announcement by President Kennedy of the establishment of a private American corporation to develop, produce, and operate their system, increases the tempo of events in this important field.

\section{MILITARY USES OF SPACE}

This aspect of space technology is one on which great emphasis is placed in the United States and undoubtedly in Russia, but to which very little attention or realization of implications has been given on this side of the Atlantic.

It is regrettable that yet a further means of military power should be available in the world, and yet inevitably space will become an arena of war, either in a passive or active sense. A quick glance at history reveals that every new medium of travel has ultimately been exploited for the purpose of war; and so it will be with space. Already prototypes of reconnaissance satellites (Samos) and satellites launched to provide early warning of ballistic missile attack (Midas) have been sent up by the Americans, and much of the work so far connected with man in space may well lead to military applications. Communication networks for military purposes will be established in space as part of, or complementary to, the civil ones discussed previously.

Controversy exists as to whether there will be a valid case for establishing nuclear weapons in orbit as further aggressive, or deterrent systems, to be cut 
down on command, to impact on predetermined places in the world. In this current age, any diversification of a deterrent system must be considered very carefully, and even though at first sight the logistics and implications of orbital bombardment weapons are arguable, the fact remains that both America and Russia have the payload capability already to place such a weapon in orbit, and it may well be in time to come, that this possibility will become reality. This could lead to the need to intercept a satellite, thus to inspect and interrogate it, to determine its purpose. Already the Americans have such projects as Saint and Slomar under consideration. The Saint programme is concerned with the development of an unmanned manoeuvrable satellite for inspection of unidentified space craft. It will probably be equipped with homing radar, television, and other instruments to relay identification data to ground stations. The first test launchings are expected in about two years, with the Atlas Agena B, launching Saint from Cape Canaveral with the intention of following the orbiting of a target satellite.

Considerable effort is being expended in America in examining the methods of actually shooting down the satellites. At first sight some of these ideas seem still in the realm of space fiction--heat rays, beamed radio-activity, nuclear fission, devices injecting clouds of small ball-bearings into collision orbits, and so on. However, such are the new problems in the environment of space, that we may well see many or, all of these techniques reaching the "hardware" stage, within the next few years.

Military space problems are a subject of a separate lecture in their own right and $I$ hope that $I$ have said enough here to hint at the importance that I think we should attach to monitoring the developments in this field.

\section{FUTURE MISSIONS}

To say that the pattern of events in space around our world, and in the solar system in the next ten years, will be fascinating and of importance to us all, is a gross understatement of fact. Activity will be in two forms-consolidation of present work leading into the deployment of operational systems, and basic research broadening and deepening new techniques of penetration of space.

I think I have said enough already about the near future with regard to the consolidation phase. So far as the other is concerned, after further Ranger tests, there will be, late in 1962, the first of a new series called "Mariner". Mariner A is scheduled for launch from Cape Canaveral by the Atlas Centaur, and will be programmed to come within 16,700 miles of Venus. An instrument package will be, aimed at the planet upon approach. The 1100-lb Mariner will be one step in NASA's deep space probe series and will be followed by Voyager, a 2,400-lb space probe designed to orbit Mars or Venus and then inject a capsule to the target planet.

So far as manned space flight is concerned the first American astronaut's flight into space is imminent and after further experiments in 1963 the USA hope to extend the Mercury capsule to the two-man Gemini craft I have mentioned. In 1965 we should see the first launching of the C5 Saturn (Fig. 8); probably by then it will be called by a different name. A successful manned lunar mission may well depend on the progress of this rocket. In the same year, the Apollo three-man capsule designed for the lunar mission will be placed in orbit around the earth. In 1966, by the use of the Saturn rocket the Apollo capsule 
should be placed in an orbit around the moon and in 1967 or '68 the Apollo craft with the three men should make its first successful landing on the moon and return to earth. If this is carried out by the Saturn C5 rocket then two rockets will be required - one to place propellant in a rocket stage in orbit around the earth to be followed by the manned capsule in the same orbit; the two then to be joined together using the rendezvous technique mentioned earlier, and the combined vehicle projected from the parking orbit near the earth to its orbit to the moon; land and return. This orbital rendezvous technique is sometimes known as the "indirect method" of lunar mission, compared to the "direct" method in which the American project Nova, a rocket of at least 4,000 tons would be required; this needs four or five stages of decreasing size, to go to the moon and return. Some reported estimates suggest that the total cost

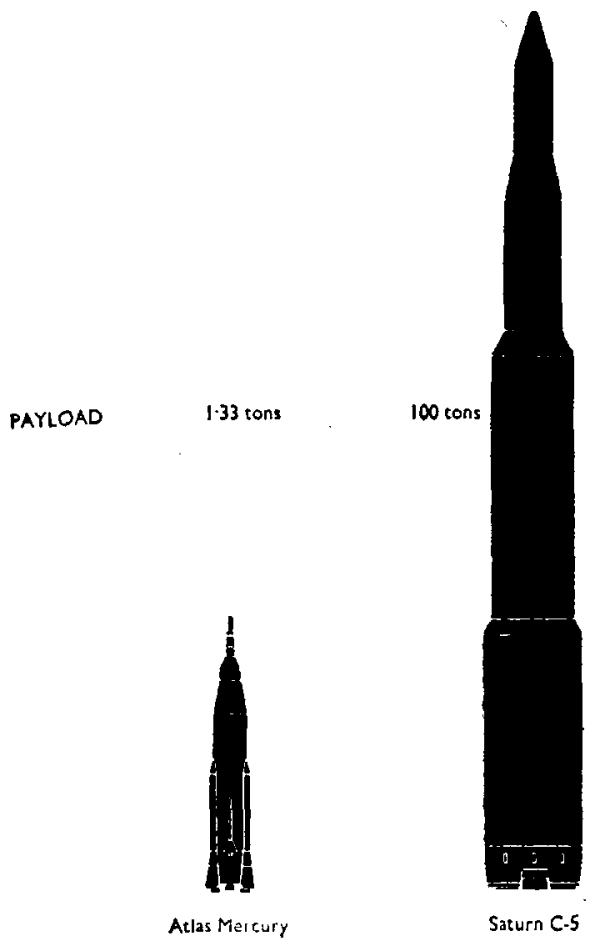

Fig. 8.-Comparison between Saturn C5 and Atlas Mercury rockets

of a programme using the indirect method would be $\$ 11,000,000,000$, only two thirds the cost of doing it by developing the new vehicle and spacecraft, the cost of which would be $\$ 16,000,000,000$. The indirect method also has more flexibility, for application to other lunar flights and a later deep space penetration.

Another project is Slomar (space logistics, maintenance, rescue) which covers the broad spectrum of space-age support requirements and spacecraft systems 
and will handle freight, passenger, maintenance, and rescue services for orbiting satellites and space stations. Slomar may also be utilized for military and scientific missions to and between satellites or space stations and the moon. The feasibility of using nuclear power for Slomar in flight, propulsion, as well as auxillary power is also under consideration. In December, 1960 as many as 6 U.S. contractors were awarded study contracts on this project, one version which is conceived as a five-man vehicle-something that looks vaguely like an enclosed five-man bobsleigh with short wings.

In America considerable thought is being given to the design of a spacecraft capable of taking off from an orthodox airfield, accelerating into orbit, staying there a considerable time to complete its mission, then to land again on a conventional airfield; a true extension of the aeroplane, and a project with a great challenge and an exciting potential.

The Russians? A similar pattern of steps towards the moon, starting in the near future with two-man orbital flights around the earth in their $4 \frac{1}{2}$-ton Vostoktype craft. In parallel with this, other orbital flights around the earth with one or possibly two men, lasting about a week. A week is approximately the duration of a return flight to the moon including a couple of days there, and it is essential to gain experience as early as possible of the effects of weightlessness on men and equipment over this period of time. The Russian booster capability and the operational use already of their Vostok craft, enables them to examine these problems in the immediate future, compared with the Americans who have to wait some time before they are in this position. This places the Russians in an advantageous position with a good start in the race to the moon. There is little doubt that the moon, which has had such fascination and dramatic ideas built up over the years, will in 10-15 years, become an important manned base for many aspects of space activity, military or civil.

I would like to finish on a note of realism. We should not forget that space is already big business, has military implications and is absorbing the extended efforts of many down-to-earth, serious-minded engineers and scientists, in many parts of the world. It is here to stay, and whilst we must clearly confine our interests to within our means, it is a new tool of mankind and we cannot, must not, ignore its implications. 


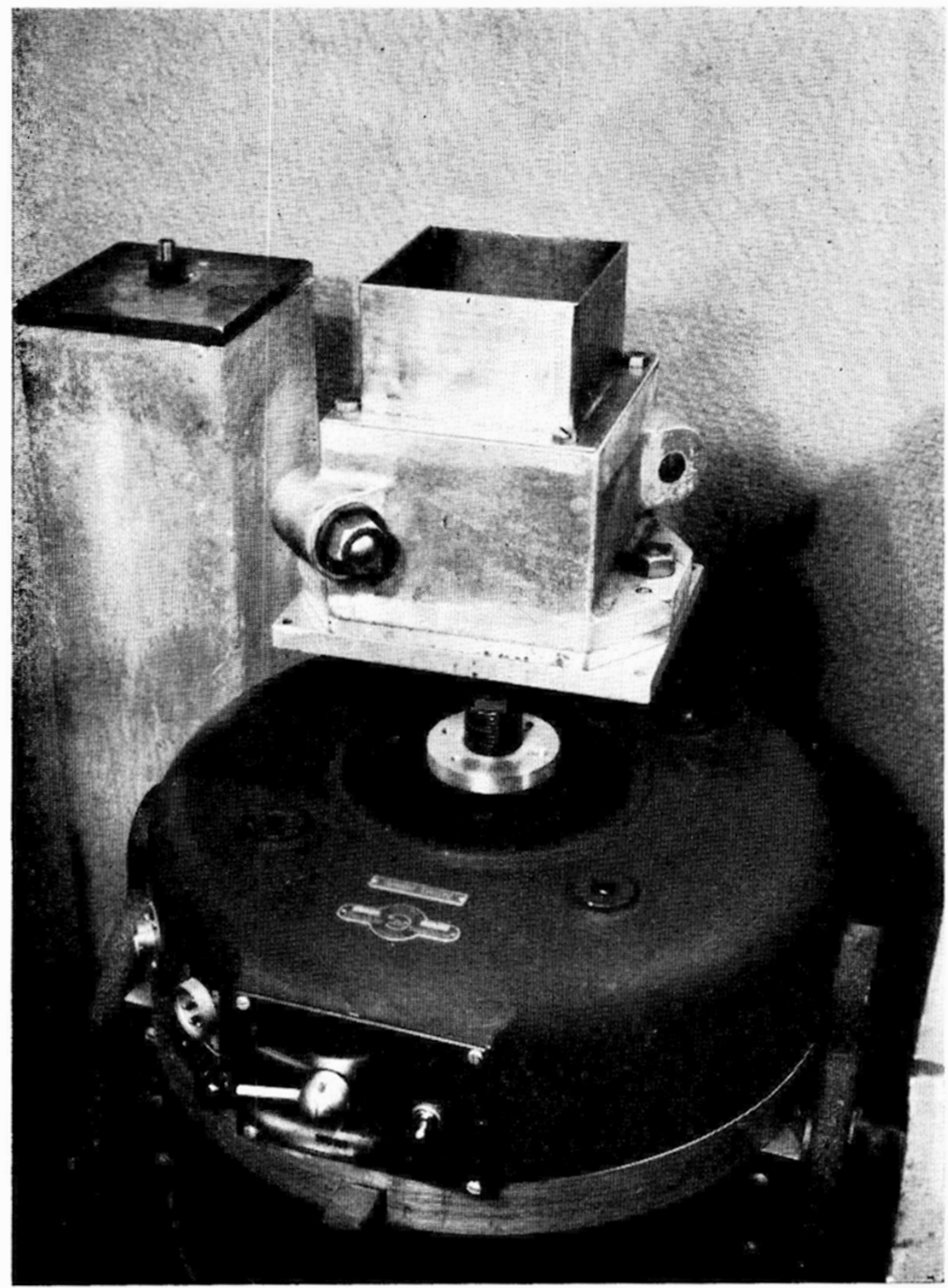

FIG. 1

Downloaded by [] on [26/04/23]. Copyright @ ICE Publishing, all rights reserved. 